\title{
Neutral Endopeptidase 24.11 in Neutrophils Modulates Protective Effects of Natriuretic Peptides Against Neutrophils-Induced Endothelial Cytotoxity
}

\author{
Toshiyuki Matsumura, Kiyotaka Kugiyama, Seigo Sugiyama, Masamichi Ohgushi, Kyozo Yamanaka, ${ }^{\star}$ Makoto Suzuki, ${ }^{\star}$ \\ and Hirofumi Yasue \\ Division of Cardiology, Kumamoto University School of Medicine, Honjo 1-1-1, Kumamoto City, Japan 860; and *Pharmacology \\ Laboratory, New Product Development Center Pfizer Pharmaceuticals Inc., 5-2, Taketoyo-cho, Chita-gun Aichi, Japan 470-23
}

\begin{abstract}
This study was performed to determine effects of atrial and brain natriuretic peptides (ANP, BNP) on neutrophilsinduced endothelial injury which is known to play a role in the pathophysiology of ischemia/reperfusion myocardial injury and to examine whether the effects of ANP and BNP on neutrophils are modulated by neutral endopeptidase 24.11 (NEP) in neutrophils themselves. The incubation of human neutrophils with ANP and BNP inhibited the neutrophils-induced detachment of cultured human endothelial cells (HEC). The inhibitory effect of ANP and BNP was associated with the suppressions of the neutrophils adhesiveness to HEC, CD18 expression on the neutrophils and elastase release from the neutrophils. Coincubation with UK73967 or phosphoramidon, inhibitors of NEP, potentiated all of the effects of ANP and BNP on the neutrophil functions, and the NEP inhibitors protected degradation of ANP and BNP by the neutrophils. NEP enzymatic activity in the particulate fractions and immunoreactive NEP expression were found to increase in the neutrophils from patients with early phase of acute myocardial infarction (AMI) by 5.2- and by 4.2-fold of the neutrophils from patients with late phase of AMI, respectively. In an in vivo canine model of myocardial ischemia/reperfusion, the intravenous administration of UK73967 suppressed the neutrophil adherence to endothelium and the neutrophil accumulation in the ischemic/reperfused myocardium. The results indicate that ANP and BNP, which are known to increase in AMI, modulate the neutrophil functions and exert protective effects against the neutrophils-induced endothelial cytotoxity. But the effects are suppressed due to their degradation by the neutrophil own NEP. Thus, neutrophil NEP, which also increases in AMI, may play a role in the pathophysiology of neutrophils-mediated ischemia/reperfusion endothelial and myocardial injury. (J. Clin. Invest. 1996. 97: 2192-2203). Key words: atrial natriuretic peptide • brain natriuretic peptide $\cdot$ CD10 - acute myocardial infarction • endothelial cells
\end{abstract}

\footnotetext{
Address correspondence to Kiyotaka Kugiyama, M.D., Division of Cardiology, Kumamoto University School of Medicine, Honjo 1-1-1, Kumamoto City, Japan 860. Phone: 96-373-5175; FAX: 96-362-3256; E-mail:miles@gpo.kumamoto-u.ac.jp

Received 20 July 1995 and accepted in revised form 22 February 1996.
}

J. Clin. Invest.

(C) The American Society for Clinical Investigation, Inc. 0021-9738/96/05/2192/12 \$2.00

Volume 97, Number 10, May 1996, 2192-2203

\section{Introduction}

Atrial natriuretic peptide $(\mathrm{ANP})^{1}$ and brain natriuretic peptide (BNP) are the hormones with a wide range of potent biological effects, including natriuresis, diuresis, vasodilations, and inhibitions of the renin-angiotensin-aldosterone system and the sympathetic nervous system (1-6). ANP is mainly synthesized and secreted from atria in adult mammals, while BNP is secreted mainly from the ventricles (7). We have reported that their plasma levels markedly increase in patients with acute myocardial infarction (AMI) $(8,9)$ as well as in those with congestive heart failure $(7,10)$. However, the role of ANP and $\mathrm{BNP}$ in the pathophysiology of AMI remains to be determined. Neutral endopeptidase 24.11 (NEP), a membrane ectoenzyme, hydrolyses and inactivates a variety of peptides including ANP and BNP at the amino side of hydrophobic amino acids (11-17). NEP is widely distributed in the body and is abundant especially in the kidney (11), lung (12), brain (13), and neutrophils (14-17). The gene of NEP has been cloned and its sequence is shown to be identical to that of a pre- $\beta$ lymphocyte surface antigen (CD10), the common acute lymphoblastic leukemia antigen (CALLA) $(18,19)$. Earlier studies indicated that NEP in neutrophils regulates their own responsiveness to multiple inflammatory peptides including formylmet-leu-phe (FMLP) and substance P (14-16). However, the functional significance of neutrophil NEP in myocardial ischemic events also remains unknown at the present time.

Myocardial ischemia/reperfusion cause coronary vascular injury as well as myocardial injury (20-24). Although the mechanism by which coronary vascular damage from myocardial ischemia/reperfusion occurs remains unclear, endothelial injury caused by the activated neutrophils has been shown to play an important role in this process (25-28). Thus, this study was aimed to determine the effects of ANP and BNP on neutrophils-induced endothelial injury and to examine whether the effects of ANP and BNP on neutrophils are modulated by NEP in neutrophils themselves.

\section{Methods}

Preparations of neutrophils. Peripheral blood neutrophils were purified from citrate-anticoagulated, dextran-sedimented venous blood samples from healthy volunteers over Ficoll-Hypaque gradients followed by hypotonic lysis of erythrocytes. The preparations were composed of $>96 \%$ neutrophils by Türk stain $(0.01 \%$ of methilrosaniline chloride and $1.0 \%$ acetic acid), neutrophil alkaline phosphatase and

1. Abbreviations used in this paper: ANP, atrial natriuretic peptide; BNP, brain natriuretic peptide; NEP, neutral endopeptidase 24.11; OZ, opsonized zymosan; HUVECs, human umbilical vein endothelial cells; HAECs, human aortic endothelial cells; MPO, myeloperoxidase. 
neutrophil esterase stain, and of $>98 \%$ viable cells by the trypan blue dye exclusion test. The isolated neutrophils were suspended in serum-free Medium 199. Neutrophils $\left(10^{6}, 5 \times 10^{6}, 10^{7}\right.$ cells $\left./ \mathrm{ml}\right)$ were incubated for the indicated time with or without ANP or BNP in the presence or absence of UK73967 (Candoxatrilat, $50 \mu \mathrm{mol} /$ liter, Pfizer Central Research), phosphoramidon (50 $\mu \mathrm{mol} / \mathrm{liter})$, or HS-142-1 (a nonpeptide antagonist for the particulate guanylyl cyclase receptor, $100 \mu \mathrm{g} / \mathrm{ml}$, Kyowa-Hakko). UK73967 and phosphoramidon have been shown to be a specific inhibitor of NEP (UK73967, NEP: $K_{\mathrm{i}}=$ $14 \mathrm{nmol} /$ liter; Angiotensin converting enzyme: $K_{\mathrm{i}}>10,000 \mathrm{nmol} / \mathrm{liter}$. Phosphoramidon, NEP: $K_{\mathrm{i}}=39 \mathrm{nmol} /$ liter, Aminopeptidase: $K_{\mathrm{i}}>$ $10,000 \mathrm{nmol} /$ liter) (29-31). Subsequently, Opsonized Zymoan (OZ, $0.5 \mathrm{mg} / \mathrm{ml})$ or C5a (20 nmol/liter) was added into the incubation mixture with neutrophils, followed by the further incubation for the indicated time at $37^{\circ} \mathrm{C}$ in the same manner as we reported previously (32). The preconditioned neutrophils were examined for the assays of elastase release, respiratory burst function, cytosolic free calcium, adhesiveness to the cultured endothelial cells and toxicity to the endothelial cells (endothelial detachment) and were also used for the examinations of NEP enzymatic activity and surface expression of CD18. Neutrophils were also isolated from the peripheral blood in patients with AMI who admitted to our hospital within $12 \mathrm{~h}$ after onset of MI. Blood sampling was performed at the admission to hospital (counted as day 0 ) and at 7:00 A.M. over $4 \mathrm{wk}$, on days 1, 2, 3, 7, 14, 21, and 28 after onset of MI. The particulate fraction prepared from neutrophils in patients with AMI was used for examination of their NEP enzymatic activity. When neutrophil surface expression of NEP/ $\mathrm{CD} 10$ was examined by fluorescence-activated cell sorter $\left(\mathrm{FACS}^{\circledR}\right)$, whole blood was directly subjected to the analysis with FACScan ${ }^{\circledR}$ (Beckton Dickinson \& Co., Mountain View, CA).

Respiratory burst function. Production of active oxygen metabolites during neutrophil activation was measured by the method of luminol-dependent chemiluminescence using the Luminescence Reader BLR-301 (ALOKA, Japan). The isolated neutrophils from the healthy volunteers $\left(5 \times 10^{6}\right.$ cells $\left./ \mathrm{ml}\right)$ suspended in $1 \mathrm{ml}$ of serum free Medium 199 without phenol red were treated with or without ANP or $\mathrm{BNP}$ in the presence or absence of UK73967 for $15 \mathrm{~min}$ at $37^{\circ} \mathrm{C}$. After the incubation, luminol ( $0.1 \mathrm{mmol} / \mathrm{liter})$ was added to the cuvette, followed by the addition of $\mathrm{OZ}(50 \mu \mathrm{g} / \mathrm{ml})$ to initiate neutrophil activation, and light emission was recorded.

Neutrophil elastase release. The isolated neutrophils from the healthy volunteers $\left(10^{7}\right.$ cells $\left./ \mathrm{ml}\right)$ suspended in $1 \mathrm{ml}$ of serum-free Medium 199 without phenol red were treated with or without ANP or BNP in the presence or absence of UK73967, phosphoramidon or HS-142-1 for $60 \mathrm{~min}$ at $37^{\circ} \mathrm{C}$. Thereafter, the cells were activated with $\mathrm{OZ}$ and then pelleted by centrifugation $(27,000 \mathrm{~g}$ for $20 \mathrm{~min})$. The hydrolytic activity of neutrophil elastase in the harvested supernatants was determined using synthetic substrate Suc-Ala-Pro-Ala-pNA as reported previously (33).

Adherence assay. Primary cultures of human umbilical vein endothelial cells (HUVECs) and the cultures of human aortic endothelial cells (HAECs) were confluently grown in 24-well plates, as we showed previously (34), and were used for this study. The isolated neutrophils from the healthy volunteers were labeled with ${ }^{51} \mathrm{Cr}$ using the method as reported previously $(35,36)$. The ${ }^{51} \mathrm{Cr}$-labeled neutrophils suspended in serum-free Medium $199\left(5 \times 10^{6}\right.$ cells $\left./ \mathrm{ml}\right)$ were treated with or without ANP or BNP in the presence or absence of UK73967 for $60 \mathrm{~min}$ at $37^{\circ} \mathrm{C}$ and then activated with $\mathrm{OZ}$. The monolayers of cultured endothelial cells were rinsed three times with serum-free Medium 199 and then incubated with the preconditioned neutrophils for $20 \mathrm{~min}$ at $37^{\circ} \mathrm{C}$ in $5 \% \mathrm{CO}_{2}$ and $98 \%$ humidity. After the incubation, the incubation medium was removed and the monolayer of the endothelial cells were washed three times with PBS to remove non-adherent neutrophils, and then remained adherent cells were lysed by an overnight incubation with $2 \mathrm{~N} \mathrm{NaOH}(1 \mathrm{ml} /$ well $)$ at $4^{\circ} \mathrm{C}$. The cell lysate was collected and ${ }^{51} \mathrm{Cr}$ activity in the lysate was counted by a Gamma Counter. The adhered neutrophils to the endothelial monolayers were expressed as a percent of the count in the to- tal neutrophils added to a well. The endothelial cells were not detached by the 20-min incubation with the neutrophils after any preconditions.

Endothelial detachment. The confluent cultures of HUVECs and HAECs grown in 12-well plates were used for the experiment $(27,28$, $37,38)$. The isolated neutrophils from the healthy volunteers $\left(10^{7}\right.$ cells $/ \mathrm{ml}$ ) were treated with or without ANP, BNP, or 8-bromo-guanosine $3^{\prime}, 5^{\prime}$-cyclic monophosphate (8-bromo-cGMP) in the presence or absence of UK73967, phosphoramidon or HS-142-1 for $60 \mathrm{~min}$ at $37^{\circ} \mathrm{C}$ and then activated with $\mathrm{OZ}$. The monolayers of cultured endothelial cells were rinsed three times with serum-free Medium 199 and then incubated with the preconditioned neutrophils at $37^{\circ} \mathrm{C}$ for 60 min in $5 \% \mathrm{CO}_{2}$ and $98 \%$ humidity. After the incubation, the detached endothelial cells and the nonadherent neutrophils were removed by three times washing with PBS. The remained nondetached endothelial cells in each well were harvested by trypsinization. The harvested nondetached endothelial cells were stained with Türk stain, and the number of nondetached endothelial cells were directly counted. The endothelial detachment was expressed as a percentage of the number of the nondetached endothelial cells isolated after the incubation with the neutrophils-free incubation mixture, which was performed in the parallel with the every condition of the incubations. There were few detached endothelial cells after the incubation with the neutrophils-free medium and variation in the counted number of the nondetached endothelial cells after the incubation with the neutrophils-free medium was $<1 \%$ among the wells. Thus, counted number of the nondetached endothelial cells after the incubation with the neutrophils-free medium can be assumed to be the cell number originally present in each well. The percent cell detachment was therefore calculated: [(the number of nondetached endothelial cells after the incubation with the neutrophils-free medium) - (the number of nondetached endothelial cells after the incubation with the preconditioned neutrophils) $] \times 100 /$ (the number of nondetached endothelial cells after the incubation with the neutrophils-free medium). To confirm that the cell detachment was due to cell injury and death in this system, the detached cells after the incubation with activated neutrophils were centrifuged, washed, and replated as described in the text. Fewer than $5 \%$ of the cells were capable of replating. The lack of viability of the detached cells was also confirmed by trypan blue staining of detached cells.

NEP enzymatic activity. The neutrophils treated with the indicated agents in $1 \mathrm{ml}$ of cold $25 \mathrm{mmol} /$ liter 2-(N-morpholino)ethanesulfonic acid (Mes) buffer ( $\mathrm{pH}$ 6.5) were homogenized with the glass to glass homogenizer and then sonicated (sonifier 250; Branson Corp., Danbury, CT) at $4^{\circ} \mathrm{C}$. The suspension was centrifuged at $800 \mathrm{~g}$ for $15 \mathrm{~min}$ at $4^{\circ} \mathrm{C}$ to remove unbroken cells and nuclear materials. The supernatant was then centrifuged at $100,000 \mathrm{~g}$ for $60 \mathrm{~min}$ at $4^{\circ} \mathrm{C}$ for separation with cytosolic and particulate fractions. The membrane pellet (particulate fractions) was resuspended in $25 \mathrm{mmol} /$ liter Mes buffer ( $\mathrm{pH}$ 6.5) containing $0.5 \%$ Triton $\mathrm{X}-100$ at $4^{\circ} \mathrm{C}$ for 90 min with continuous mixing. NEP enzymatic activity in the soluble particulate fraction and the cytosolic fraction of the isolated neutrophils was measured by a two-step spectrofluorometric assay using GlutarylAla-Ala-Phe-4-methoxy-2-naphtylamide (4Meo-2NA) as a substrate as reported previously $(12,14,16,19,39)$. The reaction was performed in the presence or absence of UK73967, and only the activity inhibited by UK73967 was attributed to the NEP activity.

Immunofluorescence staining and fluorescence-activated cell sorter (FACS) analysis. Cell surface NEP expression in neutrophils was detected by direct immunofluorescence evaluated by the flow cytometry. Aliquots of whole blood were pretreated for 5, 15, 30, and 60 min at $37^{\circ} \mathrm{C}$ with $\mathrm{OZ}$ or $\mathrm{C} 5 \mathrm{a}$, and then fixed in $1 \%$ paraformaldehyde. A part of whole blood was pretreated with ANP or BNP and then activated with $\mathrm{OZ}$ or C5a. After the pretreatments, $100 \mu \mathrm{l}$ of the blood was incubated for $30 \mathrm{~min}$ at $4^{\circ} \mathrm{C}$ in the dark with saturating concentrations $(5 \mu \mathrm{l})$ of the conjugated murine anti-human CD10/NEP (MoAb, J5-FITC; Coulter Immunology, Hialeah, FL) or the nonspecific IgG2a. After the incubation, the blood was washed in PBS con- 
taining $1 \%$ fetal calf serum (FCS) and $0.1 \% \mathrm{NaN}_{3}$. Thereafter, erythrocytes in the blood were lysed by adding $2 \mathrm{ml}$ of ice-cold erythrocyte-lysing solution $\left(\mathrm{NH}_{4} \mathrm{Cl} 2.08\right.$ grams; $\mathrm{Na}_{2}$ EDTA 0.0108 grams; $\mathrm{NaHCO}_{3} 0.21$ grams in $250 \mathrm{ml} \mathrm{H} \mathrm{H}_{2} \mathrm{O}$ ). The remained leukocytes were then rinsed again with PBS containing $1 \% \mathrm{FCS}$ and $0.1 \% \mathrm{NaN}_{3}$ and analyzed using FACScan. Antigen expression was expressed as the mean channel of fluorescence intensity of 10,000 cells.

Cell surface CD18 of the isolated neutrophils was also detected by direct immunofluorescence evaluated by the flow cytometry. The isolated neutrophils from the healthy volunteers were resuspended at a final concentration of $10^{6} \mathrm{cells} / \mathrm{ml}$ in serum-free Medium 199 without phenol red. Aliquots of cells were then pretreated with or without ANP or BNP in the presence or absence of UK73967 at $37^{\circ} \mathrm{C}$ for 10 min and subsequently incubated with $\mathrm{OZ}$ for $10 \mathrm{~min}$ and then fixed in $1 \%$ paraformaldehyde. After the incubation, the cells were washed with PBS containing $1 \%$ FCS and $0.1 \% \mathrm{NaN}_{3}$ and then incubated in the dark at $4{ }^{\circ} \mathrm{C}$ for 30 min with the conjugated murine antihuman CD18 (MoAb, FITC-Conjugated MHM23, DAKO A/S, Denmark) or the nonspecific IgG1 at a final concentration of $10 \mu \mathrm{l}$ of MoAb per $100 \mu \mathrm{l}$ of cell suspension. After the cells were washed with PBS containing $1 \% \mathrm{FCS}$ and $0.1 \% \mathrm{NaN}_{3}, \mathrm{CD} 18$ expression on neutrophils was analyzed by FACScan.

Measurement of cGMP levels. The isolated neutrophils from the healthy volunteers $\left(10^{7} \mathrm{cells} / \mathrm{ml}\right)$ were incubated with ANP $(1 \mathrm{nmol} / \mathrm{li}-$ ter) or $\mathrm{BNP}(1 \mathrm{nmol} /$ liter $)$ at $37^{\circ} \mathrm{C}$ for $10 \mathrm{~min}$ in the presence or absence of UK73967. The incubations were done in the presence of 3-isobutyl-1-methylxanthine (IBMX; $1 \mathrm{mmol} /$ liter). The reaction was terminated by the addition of trichloroacetic acid (TCA, final concentration $6 \%$ ). The cell mixture was then sonicated. After centrifugation of the mixture, the supernatant was harvested and extracted with diethyl ether. After the extraction of TCA, cGMP produced in neutrophils was measured using a standard radioimmunoassay kit $\left({ }^{125} \mathrm{I}-\right.$ cGMP; Amersham).

Gel filtration analysis of ${ }^{125} I$-ANP hydrolysis by neutrophils. ${ }^{125} \mathrm{I}-$ labeled $\alpha$-human ANP ( $40 \mu \mathrm{l}, 2000 \mathrm{Ci} / \mathrm{mmol})$ was incubated for 15 $\min$ at $37^{\circ} \mathrm{C}$ with or without the activated neutrophils or the particulate fractions prepared from the activated neutrophils in serum-free Medium 199 in the presence or absence of UK73967 (50 $\mu \mathrm{mol} / \mathrm{liter})$. After the termination of the incubation by the addition of EDTA (10 $\mathrm{mmol} /$ liter), the incubation mixture was centrifuged, and the resulting supernatant $(400 \mu \mathrm{l})$ was subjected to the Sephadex G-25 gel filtration chromatography (Superfine, $1.2 \times 80 \mathrm{~cm}$, Pharmacia) at a flow rate of $5 \mathrm{ml} / \mathrm{h}$ with $1 \mathrm{ml} /$ tube of the fraction size. The chromatography was calibrated with ${ }^{125} \mathrm{I}$-labeled standards of ${ }^{125} \mathrm{I}$-ANP, ${ }^{125} \mathrm{I}$-Phe-ArgTyr, free ${ }^{125} \mathrm{I}$ in the identical manner. Phe-Arg-Tyr was iodinated as reported previously (40).

Measurements of cytosolic free calcium in neutrophils. The concentration of cytosolic free calcium $\left(\left[\mathrm{Ca}^{2+}\right]_{\mathrm{i}}\right)$ in neutrophils was measured using the calcium indicator fura 2 , as described previously (41-43). In short, the isolated neutrophils $\left(10^{6} \mathrm{cells} / \mathrm{ml}\right)$ from the healthy volunteers were incubated with $2 \mu \mathrm{mol} /$ liter fura $2 / \mathrm{AM}$ in phosphate buffer containing $0.1 \%$ bovine serum albumin at $37^{\circ} \mathrm{C}$ for $45 \mathrm{~min}$. After this, the neutrophils were washed twice with the incubation medium and resuspended at a final concentration of $10^{6} \mathrm{cells} / \mathrm{ml}$ in phenol red-free Medium 199. Thereafter, the loaded neutrophils were treated with or without ANP, BNP and 8-bromo-cGMP in the presence or absence of HS-142-1 for $15 \mathrm{~min}$ at $37^{\circ} \mathrm{C}$. Then, cell suspension $(100 \mu \mathrm{l})$ was directly plated onto the tissue culture dish. Immediately after plating, a single cell was centered in the measuring field of the microscope photometer while it was still in suspension. Continuous monitoring of $\left[\mathrm{Ca}^{2+}\right]_{\mathrm{i}}$ was made in a single cell as it began to attach to the dishes. 5 min after plating of the neutrophils, C5a was added to the medium under the continuous monitoring of $\left[\mathrm{Ca}^{2+}\right]_{i} \cdot\left[\mathrm{Ca}^{2+}\right]_{\mathrm{i}}$ monitoring in a single fura 2 loaded neutrophils was continuously performed by the dual excitation microfluorimetry equipment (ARGUS 50/CA System, HAMAMATSU, Japan) coupled to an image acquisition system (Nikon inverted microscope, Nikon, Japan). This system was also equipped with a thermostated chamber allowing the cells to be main- tained at $37^{\circ} \mathrm{C}$ during the entire experiment. The ratio of the fluorescence $(\mathrm{R}=\mathrm{F} 340 / \mathrm{F} 380)$ was calibrated to express $\left[\mathrm{Ca}^{2+}\right]_{\mathrm{i}}$ using the formula, proposed previously $(43,44)$.

In vivo animal experiments. Healthy adult beagle dogs (10.0$13.0 \mathrm{~kg}$ ) of either sex were anesthetized with sodium pentobarbital $(30 \mathrm{mg} / \mathrm{kg})$, intubated, and ventilated with room air by an animal respirator. The hearts were exposed through a left thoracotomy in the fifth intercostal space. The left anterior descending coronary artery (LAD) was then exposed and carefully dissected free immediately distal to the first major diagonal branch. Regional myocardial ischemia was produced by occluding LAD for $90 \mathrm{~min}$ and was followed by $2 \mathrm{~h}$ of reperfusion. UK73967 (1 mg/kg) and its vehicle were intravenously administered in $7 \mathrm{dogs}$ and $7 \mathrm{dogs}$, respectively, as a bolus twice at $30 \mathrm{~min}$ after the LAD occlusion and at the beginning of the reperfusion. Blood samples were obtained from femoral vein. Arterial blood pressure, heart rate, and electrocardiogram were recorded continuously. Plasma ANP concentration was measured by radioimmunoassay using a commercial kit (Shionoria ANP kit, Osaka, Japan).

After the $2 \mathrm{~h}$ of reperfusion, heparin (10,000 units) was given intravenously and then the heart was stopped with an overdose of pentobarbital and removed from the chest. The left and right coronary arteries were cannulated and perfused with cold saline at a pressure of $75 \mathrm{mmHg}$ for $30 \mathrm{~min}$. Thereafter, five pieces of myocardial tissue samples (300-500 mg) were punched out from both central myocardial regions perfused by LAD and the left circumflex coronary artery (LCx), respectively. A part of each sample was fixed in $10 \%$ buffered formalin for histologic analysis with light microscopy. The remaining part of each sample from the region perfused by LAD was sectioned into small cubes and incubated in $0.1 \%$ nitroblue tetrazolium (NBT) in phosphate buffer at $\mathrm{pH} 7.4$ and $37^{\circ} \mathrm{C}$ for $15 \mathrm{~min}$ to identify the injured tissue $(45,46)$. The tissue samples, from LAD region, that showed the negative NBT staining (the injured tissue) and the tissue samples from LCx region (the control tissue) were analyzed for myocardial myeloperoxidase activity (MPO) assay. The NBT staining did not affect MPO assay (46). Subsequently, each heart was perfused with $3 \%$ glutaraldehyde at a pressure of $75 \mathrm{mmHg}$ for $30 \mathrm{~min}$, then LAD $1 \mathrm{~cm}$ distal to the occlusion site and LCx were removed and used for the analysis with scanning electron microscopy.

Assay of myocardial myeloperoxidase (MPO). The enzyme MPO is found in the granules of neutrophils and has been used as an indicator of neutrophil emigration into tissue $(45,47)$. The injured myocardial tissue determined by NBT staining and the control tissue were homogenized and sonicated in $0.5 \%$ hexadecyltrimethylammonium bromide (HTAB) in $50 \mathrm{mmol} /$ liter potassium phosphate buffer, $\mathrm{pH}$ 6.0. The mixture was centrifuged at $12,500 \mathrm{~g}$ for $30 \mathrm{~min}$ at $4^{\circ} \mathrm{C}$. The supernatants were then collected and reacted with $0.167 \mathrm{mg} / \mathrm{ml}$ of $o$-dianisidine dihydrochloride and $0.0005 \% \mathrm{H}_{2} \mathrm{O}_{2}$ in $50 \mathrm{mmol} / \mathrm{liter}$ phosphate buffer at $\mathrm{pH}$ 6.0. The change in absorbance was measured spectrophotometrically at $460 \mathrm{~nm}$. One unit of myeloperoxidase is defined as the quantity of enzyme hydrolyzing $1 \mathrm{mmol}$ peroxide/ $\min$ at $25^{\circ} \mathrm{C}$.

Scanning electron microscopy of coronary arteries and light microscopy of myocardial tissues. The coronary arteries removed from the heart were then placed in 3\% glutaraldehyde in $0.1 \mathrm{~mol} / \mathrm{liter}$ phosphate buffer for $24 \mathrm{~h}$, and then the arteries were cut into longitudinal-sections with razor blades to expose the luminal surface. The sections were immersed in $1 \%$ tannic acid (Katayama Chemical Inc., Osaka, Japan) in phosphate buffer overnight at $4^{\circ} \mathrm{C}$ to increase tissue reactivity with osmium tetroxide (so-called "conductive-staining"). The sections were then rinsed with water for $2 \mathrm{~h}$ and fixed with $1 \%$ $\mathrm{OsO}_{4}$ in distilled water for $2 \mathrm{~h}$ at $4^{\circ} \mathrm{C}$. The specimens were dehydrated in ethanol series, infiltrated in $100 \% \mathrm{t}$-butanol, frozen, freeze-dried by evaporation under vacuum, mounted on aluminum stubs, and coated with a 20 to $30 \mathrm{~nm}$ layer of platinum alloy in a ion coater (Eiko Engineering Inc., Ibaragi, Japan). The specimens were observed at an accelerating voltage of $15 \mathrm{kV}$ with a JSM $6400 \mathrm{FK}$ scanning electron microscope (JEOL Inc., Tokyo, Japan). 
Myocardial tissues from regions perfused by LAD and LCx were fixed in $10 \%$ phosphate buffered formalin, embedded in paraffin, sectioned, and stained with hematoxylin and eosin.

Antibodies and reagents. $\alpha$-Human ANP, BNP-32 (Human), and Suc-Ala-Pro-Ala-pNA were obtained from Peptide Institute, Inc., Minoh, Japan. UK73967 was supplied by Pfizer Central Research, Sandwich, UK. HS-142-1 was supplied by Kyowa-Hakko, Tokyo, Japan. A mouse anti-human CD10 MoAb (J5-FITC, IgG2a) was obtained from Coulter Immunology, Hialeah, FL. A mouse anti-human CD18 MoAb (FITC-Conjugated MHM23, IgG1) was from DAKO A/S, Denmark. cGMP radioimmunoassay kit, ${ }^{51} \mathrm{Cr}$, ${ }^{125} \mathrm{I}$, and ${ }^{125} \mathrm{I}$-labeled $\alpha$-human ANP were from Amersham, Buckinghamshire, UK. PheArg-Tyr was from BACHEM, Bubendorf, Switzerland. All reagents for cell culture were from GIBCO (Grand Island, NY). Other chemicals were from Sigma Chemical Co. (St. Louis, MO).

Statistical analysis. All values were expressed as mean \pm SEM. Statistical analysis of the data was performed by Student's $t$ test for paired or unpaired observations. When more than two groups were compared, ANOVA was used. Values were considered to be statistically different at $P<0.05$.

\section{Results}

The inhibitory effects of ANP or BNP on the neutrophil functions and their potentiations by NEP inhibitor. The pretreatment of neutrophils with ANP or BNP inhibited endothelial detachment by the activated neutrophils in a dose-dependent manner (Fig. 1). The adhesiveness of the activated neutrophils to the
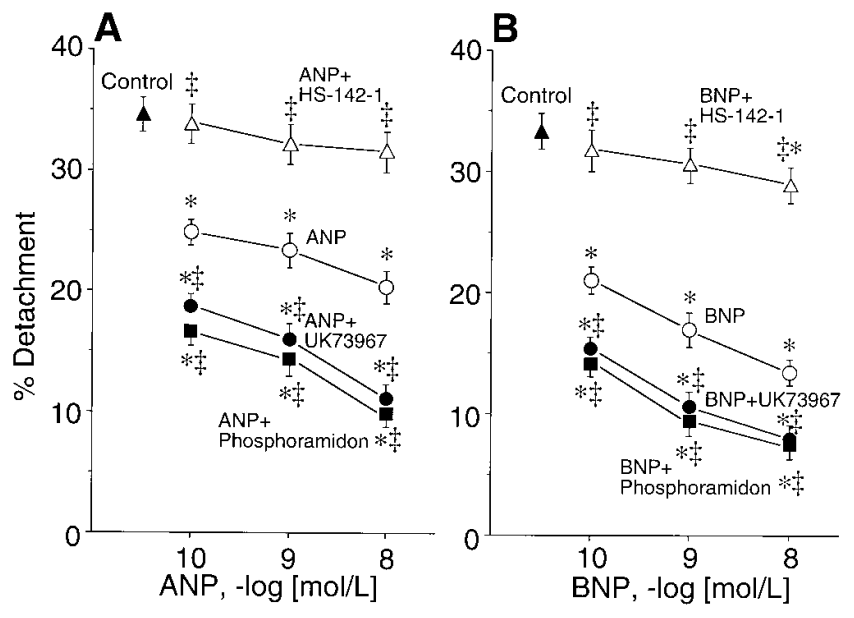

Figure 1. Effects of ANP and BNP in the combination with or without UK73967, phosphoramidon or HS-142-1 on the neutrophilsinduced endothelial cell detachment. The isolated neutrophils from the healthy volunteers $\left(10^{7}\right.$ cells $\left./ \mathrm{ml}\right)$ were pretreated with ANP $(A)$ or BNP $(B)$ in the presence or absence of UK73967 (a specific inhibitor of NEP, $50 \mu \mathrm{mol} /$ liter), phosphoramidon (50 $\mu \mathrm{mol} / \mathrm{liter}$ ), HS-142-1 (an antagonist for the particulate guanylyl cyclase receptor, $100 \mu \mathrm{g} /$ $\mathrm{ml}$ ), and the pretreated neutrophils were subsequently activated with $\mathrm{OZ}$, and the preconditioned neutrophils were incubated with the monolayer of the cultured HUVECs, as described in the text. (A) Control, activated neutrophils with no pretreatment; $(O)$ activated neutrophils after pretreatment with ANP or BNP; $(\triangle)$ activated neutrophils after pretreatment with ANP or BNP in the presence of HS$142-1 ;(-)$ activated neutrophils after pretreatment with ANP or BNP in the presence of UK73967; ( $)$ activated neutrophils after pretreatment with ANP or BNP in the presence of phosphoramidon. Values are shown as mean $\pm \operatorname{SEM}(n=6-10) . * P<0.01$ vs. control $(\mathbf{\Lambda}) ;{ }^{\ddagger} P<0.01$ vs. activated neutrophils after pretreatment with ANP or $\mathrm{BNP}(\bigcirc)$.

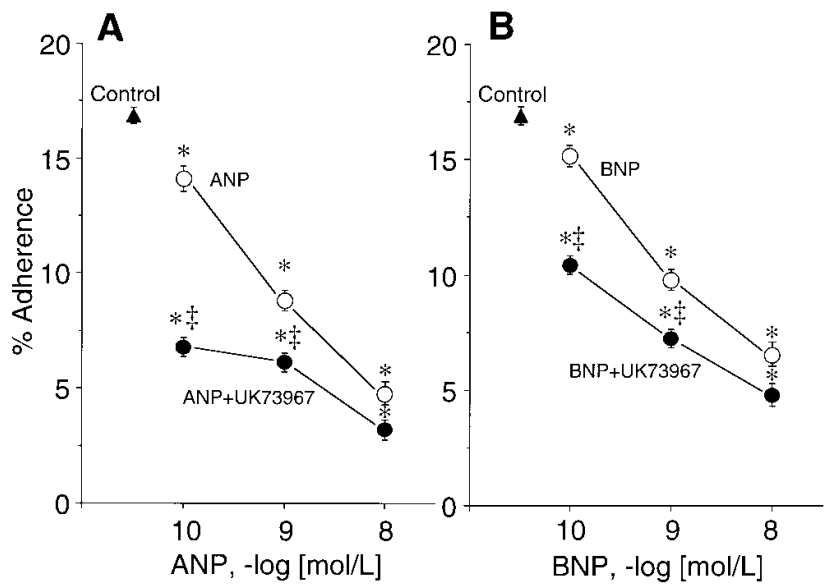

Figure 2. Effects of ANP and BNP in the combination with or without UK 73967 on the neutrophils adherence to endothelial cells. ${ }^{51} \mathrm{Cr}$ labeled neutrophils $\left(5 \times 10^{6} \mathrm{cells} / \mathrm{ml}\right)$ from the healthy volunteers were activated with $\mathrm{OZ}$ after pretreatment with ANP $(A)$ or BNP $(B)$ in the presence or absence of UK73967 (a specific inhibitor of NEP, $50 \mu \mathrm{mol} / \mathrm{liter}$ ), and the preconditioned neutrophils were incubated with the monolayer of the cultured HUVECs, as described in the text. ( $\Delta$ ) Control, activated neutrophils with no pretreatment; $(\bigcirc)$ activated neutrophils after pretreatment with ANP or BNP; $(\bullet)$ activated neutrophils after pretreatment with ANP or BNP in the presence of UK73967 (a specific inhibitor of NEP, $50 \mu \mathrm{mol} / \mathrm{liter}$ ). Values are shown as mean $\pm \operatorname{SEM}(n=6-10) .{ }^{*} P<0.01$ vs. control $(\mathbf{\Delta}) ;{ }^{\ddagger} P<$ 0.01 vs. activated neutrophils after pretreatment with ANP or BNP $(\bigcirc)$.

cultured endothelial cells (Fig. 2) and elastase release from the activated neutrophils (Fig. 3) were also inhibited by the pretreatment of neutrophils with ANP or BNP in a dose-dependent manner. Co-incubation of the neutrophils with UK73967

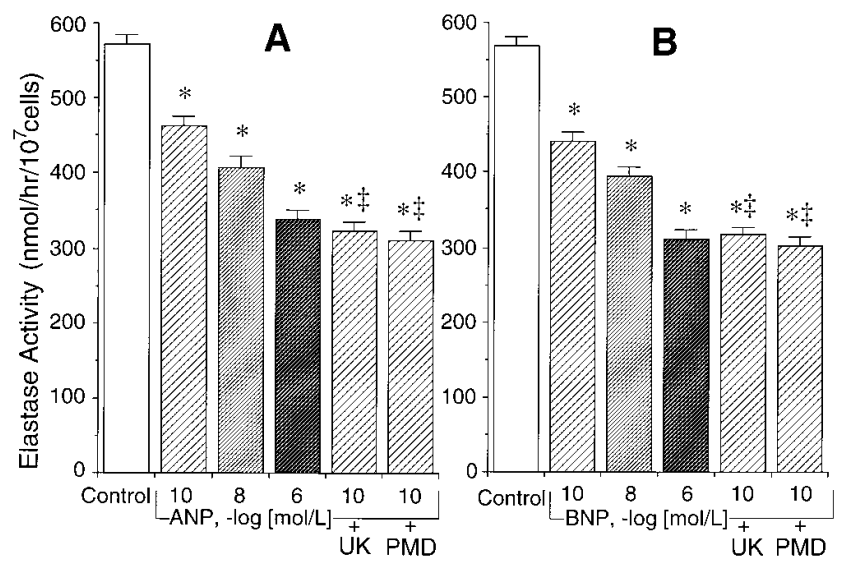

Figure 3. Effects of ANP and BNP in the combination with or without UK 73967 or phosphoramidon on elastase release from the isolated neutrophils. The isolated neutrophils from the healthy volunteers $\left(10^{7}\right.$ cells $\left./ \mathrm{ml}\right)$ suspended in $1 \mathrm{ml}$ of serum-free Medium 199 without phenol red were activated with $\mathrm{OZ}$ after pretreatment with or without ANP $(A)$ or BNP $(B)$ in the presence or absence of UK73967 (a specific inhibitor of NEP, $50 \mu \mathrm{mol} /$ liter), or phosphoramidon (PMD, $50 \mu \mathrm{mol} / \mathrm{liter}$ ) for $60 \mathrm{~min}$ at $37^{\circ} \mathrm{C}$, as described in the text. Values are shown as mean $\pm \operatorname{SEM}(n=6-10)$. $* P<0.01$ vs. control (activated neutrophils with no pretreatment); ${ }^{\ddagger} P<0.01$ vs. activated neutrophils after pretreatment with ANP ( $0.1 \mathrm{nmol} / \mathrm{liter})$ alone or BNP (0.1 nmol/liter) alone, respectively. 
Table I. Effects of ANP or BNP on Reactive Oxygen Production of Neutrophils Activated with $\mathrm{OZ}$

\begin{tabular}{lcc}
\hline \multicolumn{1}{c}{ Treatments } & Integrated count $\left(\mathrm{cpm} \times 10^{3}\right)^{*}$ & Peak count $\left(\mathrm{cpm} \times 10^{3}\right)^{\ddagger}$ \\
\hline No pretreatment & $1.1 \pm 0.1$ & $0.1 \pm 0.1$ \\
OZ alone & $117.8 \pm 6.9^{\S}$ & $11.0 \pm 0.6^{\S}$ \\
$\mathrm{ANP}+\mathrm{OZ}$ & $114.5 \pm 5.2^{\S}$ & $10.5 \pm 0.4^{\S}$ \\
$\mathrm{ANP}+\mathrm{UK} 73967+\mathrm{OZ}$ & $113.9 \pm 8.5^{\S}$ & $10.1 \pm 0.8^{\S}$ \\
$\mathrm{BNP}+\mathrm{OZ}$ & $116.7 \pm 3.0^{\S}$ & $10.4 \pm 0.4^{\S}$ \\
$\mathrm{BNP}+\mathrm{UK} 73967+\mathrm{OZ}$ & $114.0 \pm 6.1^{\S}$ & $10.3 \pm 0.5^{\S}$ \\
& & \\
\hline
\end{tabular}

Details of the method were described in the text. *Integrated count means the sum of chemiluminescence counts integrated for $15 \mathrm{~min}$ after the activation. ${ }^{\ddagger}$ Peak count means the maximal counts within $15 \mathrm{~min}$ after the activation. Concentrations of ANP, BNP, and UK73967 were 1 $\mathrm{nmol} /$ liter, $1 \mathrm{nmol} / \mathrm{liter}$, and $50 \mu \mathrm{mol} /$ liter, respectively. Values are shown as mean $\pm \operatorname{SEM}(n=6-10) .{ }^{\S} P<0.01$ vs. no pretreatment.

or phosphoramidon potentiated the inhibitory effects of ANP or BNP on the neutrophils-induced endothelial detachment, the adhesiveness of the neutrophils to the endothelial cells and on the elastase release from the neutrophils (Figs. 1-3). The inhibitory effects of ANP or BNP on the adhesion of neutrophils to endothelium and neutrophils-mediated endothelial detachment and their potentiation by NEP inhibitor were comparable between the experiments using HUVECs and those using HAECs (data not shown). The pretreatment of neutrophils with UK73967 or phosphoramidon alone had no effect on elastase release from the activated neutrophils (elastase activity $\left[\mathrm{nmol} / \mathrm{h} / 10^{7}\right.$ cells]: control; 573 \pm 10 , UK73967 alone; $570 \pm 11$, phosphoramidon alone; $569 \pm 10, n=6-10, P=\mathrm{NS}$ ) and also had no effect on the neutrophils adhesion to the endothelial cells and endothelial detachment by the neutrophils (data not shown). The pretreatment with ANP or BNP had no effect on the total and peak chemiluminescence counts of the neutrophils activated with $\mathrm{OZ}$ as shown in Table I.

The studies with flow cytometry showed that the pretreatment of neutrophils with ANP or BNP inhibited CD18 expression on the activated neutrophils (Table II). Co-incubation with UK73967 potentiated the inhibitory effect of ANP or BNP on CD18 expression on the activated neutrophils. The

Table II. Cell Surface CD18 Expression on Isolated Neutrophils

\begin{tabular}{ll}
\hline \multicolumn{1}{c}{ Treatments } & Mean channel of fluorescence intensity \\
\hline No pretreatment & $37.0 \pm 0.4$ \\
OZ alone & $67.3 \pm 1.2$ \\
ANP+OZ & $58.0 \pm 1.6^{*}$ \\
ANP+UK73967+OZ & $38.0 \pm 0.3^{* \ddagger}$ \\
BNP+OZ & $44.7 \pm 0.8^{*}$ \\
BNP+UK73967+OZ & $39.0 \pm 1.0^{* \ddagger}$ \\
UK73967+OZ & $67.1 \pm 1.0$ \\
\hline
\end{tabular}

Cell surface CD18 immunoreactive expression was analyzed using FACScan. Details of the method were described in the text. Concentrations of ANP, BNP, and UK73967 were $1 \mathrm{nmol} / \mathrm{liter}, 1 \mathrm{nmol} / \mathrm{liter}$, and $50 \mu \mathrm{mol} /$ liter, respectively. Values are shown as mean $\pm \operatorname{SEM}(n=6-$ 10). ${ }^{*} P<0.01$ vs. $\mathrm{OZ}$ alone; ${ }^{\ddagger} P<0.01$ vs. $\mathrm{ANP}+\mathrm{OZ}$ or $\mathrm{BNP}+\mathrm{OZ}$.
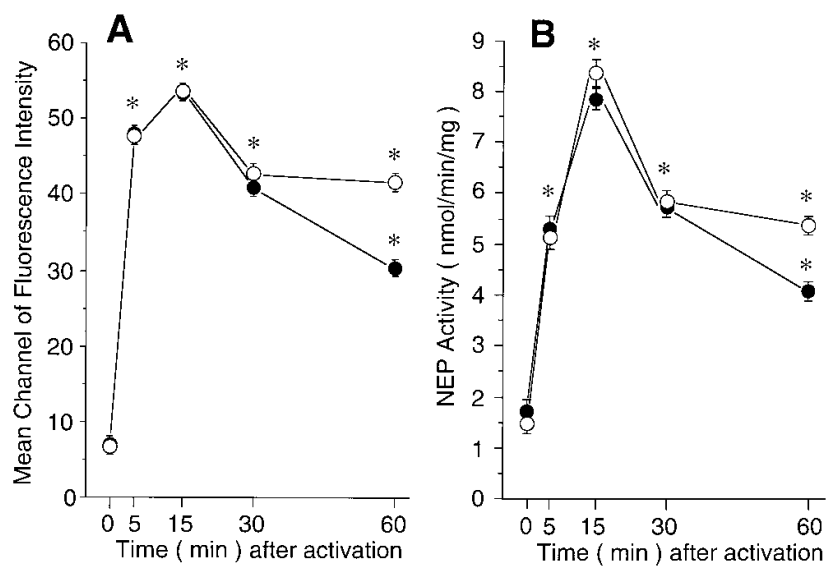

Figure 4. Time courses of NEP/CD10 immunoreactive expression and NEP enzymatic activity on the surface membrane of the human neutrophils stimulated with OZ or C5a. (A) NEP immunoreactive expression. (B) NEP enzymatic activity. ( $\bigcirc)$ Neutrophils activated by $\mathrm{OZ} ;(-)$ neutrophils activated by C5a. Values are shown as mean $\pm \operatorname{SEM}\left(n=6\right.$ in each experiment), ${ }^{*} P<0.01$ vs. time 0 (before activation).

pretreatment of neutrophils with UK73967 alone had no effect on CD18 expression on the activated neutrophils.

NEP enzymatic activity and immunoreactive expression on the surface membrane of neutrophils. NEP enzymatic activity in the particulate fraction and NEP/CD10 immunoreactive expression on the surface membrane of neutrophils were up-regulated within $5 \mathrm{~min}$ after the exposure to OZ or C5a (Fig. 4). The NEP enzymatic activity and NEP/CD10 immunoreactive expression on the surface membrane of neutrophils from the peripheral blood in patients with AMI were also up-regulated in the early phase of AMI (Figs. 5 and 6), but the NEP expressions were gradually decreased and returned to the same levels of control subjects within $7 \mathrm{~d}$ after the MI onset. In contrast with the NEP activity in the cell surface membrane, the activ-

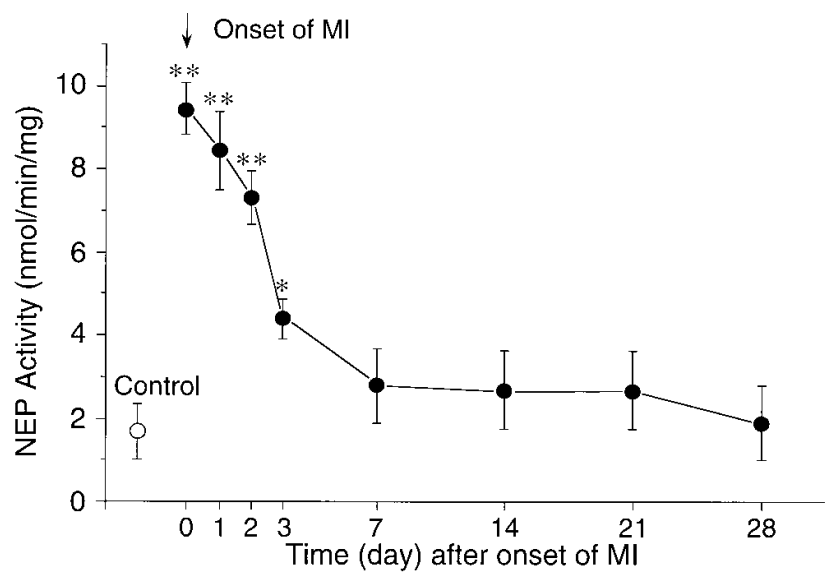

Figure 5. Time course of human neutrophil membrane NEP enzymatic activity in patients with acute myocardial infarction (AMI). Neutrophil NEP enzymatic activity in the particulate fraction of neutrophils from patients with AMI $(\bullet, n=8)$ and of neutrophils from control subjects $(\mathrm{O}, n=6)$. Details of the method were described in the text. Values are shown as mean \pm SEM, ${ }^{*} P<0.05,{ }^{* *} P<0.01$ vs. control subjects $(\bigcirc)$. 


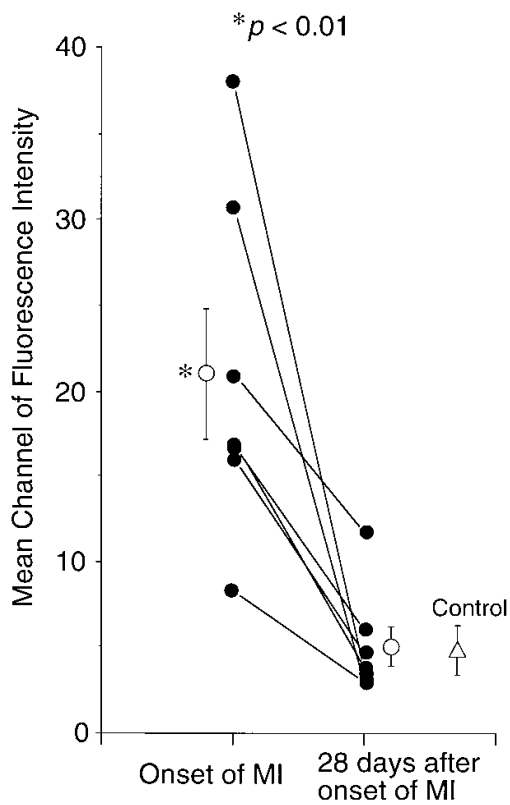

Figure 6. FACS analysis of human neutrophil $\mathrm{NEP} / \mathrm{CD} 10$ immunoreactive expression in patients with acute myocardial infarction (AMI). Details of the method were described in the text. $* P<0.01$ vs. 28th day after MI onset and control subjects $(\Delta)$

ity in the cytosolic fraction decreased in neutrophils activated with OZ and in those from patients with early phase of AMI as shown in Table III. Total NEP activity in the particulate plus cytosolic fractions of neutrophils activated with $\mathrm{OZ}$ and of neutrophils from patients with early phase of AMI was not significantly different from that of nonactivated neutrophils and neutrophils in patients with late phase of AMI, respectively (Table III). Pretreatment of neutrophils with cycloheximide or actinomycin D did not affect the up-regulations of NEP enzymatic activity or immunoreactive expression on the surface membrane of the activated neutrophils (Table IV). Pretreatment with ANP or BNP did not affect the up-regulation of NEP/CD10 immunoreactive expression on the surface membrane of the activated neutrophils (mean channel of fluores-

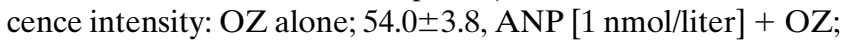

Table III. Neutrophil NEP Activities in the Particulate and Cytosolic Fractions

\begin{tabular}{|c|c|c|c|}
\hline Samples & Particulate & Cytosol & Total activity \\
\hline & $\%$ of total activity & $\%$ of total activity & $\mathrm{nmol} / \mathrm{min} / \mathrm{mg}$ \\
\hline No treated & & & \\
\hline neutrophils & $21.9 \pm 2.4$ & $78.1 \pm 2.5$ & $8.6 \pm 0.4$ \\
\hline Activated & & & \\
\hline neutrophils & $97.0 \pm 1.3^{*}$ & $3.0 \pm 0.8^{*}$ & $8.8 \pm 0.1$ \\
\hline Neutrophils in & & & \\
\hline late phase of AMI & $18.6 \pm 1.8$ & $81.4 \pm 2.4$ & $9.4 \pm 0.3$ \\
\hline $\begin{array}{l}\text { Neutrophils in } \\
\text { early phase of AMI }\end{array}$ & $97.2 \pm 1.4^{\ddagger}$ & $2.8 \pm 0.1^{\ddagger}$ & $9.6 \pm 0.2$ \\
\hline
\end{tabular}

No treated neutrophils, neutrophils isolated from healthy volunteers were treated without $\mathrm{OZ}$ but in the identical manner with neutrophils activation with OZ; Activated neutrophils, neutrophils isolated from healthy volunteers were incubated with OZ; Neutrophils in late phase of AMI, neutrophils isolated from the peripheral circulation in patients with AMI on 28th day after onset; Neutrophils in early phase of AMI, neutrophils isolated from the peripheral circulation in patients with AMI on the day of the onset. Values are shown as mean \pm SEM $(n=$ 6-10). ${ }^{*} P<0.01$ vs. no treated neutrophils; ${ }^{\ddagger} P<0.01$ vs. neutrophils in late phase of AMI.

Table IV. Effects of Cycloheximide or Actinomycin D on the NEP Enzymatic Activity and Immunoreactive Expression on the Surface Membrane of the Activated Neutrophils

\begin{tabular}{lcc}
\hline \multicolumn{1}{c}{ Treatment } & $\begin{array}{c}\text { Mean channel of } \\
\text { fluorescence intensity }\end{array}$ & NEP activity \\
\hline & & $n m o l / m i n / m g$ \\
No treatment & $7.9 \pm 0.6$ & $3.3 \pm 0.2$ \\
OZ alone & $54.0 \pm 3.8^{*}$ & $8.5 \pm 0.3^{*}$ \\
Cycloheximide $+\mathrm{OZ}$ & $53.9 \pm 1.8^{*}$ & $8.6 \pm 0.4^{*}$ \\
Actinomycin D+OZ & $53.3 \pm 2.2^{*}$ & $8.7 \pm 0.2^{*}$ \\
& & \\
\hline
\end{tabular}

Details were described in the text. No treatment, neutrophils from healthy volunteers were treated without $\mathrm{OZ}$ but in the identical manner with neutrophils activation with $\mathrm{OZ}$; $\mathrm{OZ}$ alone, neutrophils from healthy volunteers were activated with OZ; Cycloheximide+OZ, neutrophils from healthy volunteers were preincubated with cycloheximide (40 $\mu \mathrm{mol} /$ liter) and subsequently activated by OZ; Actinomycin $\mathrm{D}+\mathrm{OZ}$, neutrophils from healthy volunteers were preincubated with actinomycin $\mathrm{D}(150 \mathrm{nmol} /$ liter $)$ and subsequently activated by $\mathrm{OZ}$. Values are shown as mean $\pm \operatorname{SEM}(n=6$ in each experiment $) .{ }^{*} P<0.01$ vs. no treatment.

54.1 $\pm 2.1, \mathrm{BNP}$ [1 nmol/liter] + OZ; 53.8 $\pm 1.8, n=6$ in each experiment, $P=\mathrm{NS})$. There were no significant differences in the NEP enzymatic activity and NEP/CD10 immunoreactive expression in the surface membrane of the neutrophils in early phase of AMI between the patients treated with and without the infusion of tissue plasminogen activator (data not shown).

Roles of cGMP on the effects of ANP and BNP. The incubation of neutrophils with ANP (1 nmol/liter) or BNP ( $1 \mathrm{nmol} /$ liter) induced cGMP generation in neutrophils, which peaked at 5-10 min and lasted for $30 \mathrm{~min}$ after the start of the incubation with ANP or BNP, and co-incubation with UK73967 potentiated the effect of ANP or BNP on cGMP generation (Fig. 7). The incubation of neutrophils with ANP or BNP in the combination with HS-142-1, an antagonist for the particulate guanylyl cyclase receptor, attenuated the inhibitory effects of ANP or BNP on the endothelial detachment by the activated neutrophils (Fig. 1) and on the elastase release from the activated neutrophils (elastase activity [nmol/h/10 cells]: control; 573 \pm 10, ANP [1 nmol/liter] alone; $430 \pm 12,{ }^{\S}$ ANP [1 nmol/liter] + HS-142-1; 520 $\pm 15,{ }^{* \S}$ BNP [1 nmol/liter] alone; $423 \pm 10,{ }^{\S}$ BNP $[1$ nmol/liter $]+$ HS-142- $1 ; 484 \pm 12,{ }^{\ddagger} n=6-10,{ }^{*} P<0.01$ vs. ANP [ $1 \mathrm{nmol} /$ liter] alone, ${ }^{\ddagger} P<0.01$ vs. BNP $[1 \mathrm{nmol} /$ liter] alone, ${ }^{\S} P<0.01$ vs. control). The pretreatment of neutrophils with 8-bromo-cGMP inhibited the endothelial detachment by the activated neutrophils (Fig. 8) and elastase release from the activated neutrophils (elastase activity [nmol/h/10 cells]: control; 573 \pm 10 , 8-bromo-cGMP [0.1 mmol/liter]; 410 \pm 19 , 8-bromo-cGMP [1 mmol/liter]; 331 $17, * n=6-10, * P<0.01$ vs. control), mimicking the results obtained from the experiment using ANP or BNP.

The effect of UK73967 on ${ }^{125}$ I-ANP degradation by neutrophils. After a 15-min incubation of ${ }^{125}$ I-ANP with the particulate fraction from the activated neutrophils, 2 main hydrolysis products were detected by gel filtration chromatography analysis; one corresponds to ${ }^{125} \mathrm{I}$-Phe-Arg-Tyr and the other corresponds to the undetermined degradation product of ${ }^{125} \mathrm{I}$-ANP presumably cleaved between residues Cys-105 and Phe-106, accompanied by a minor peak corresponding to free ${ }^{125} \mathrm{I}$ (Fig. 9). When ${ }^{125}$ I-ANP was incubated with the activated neutro- 


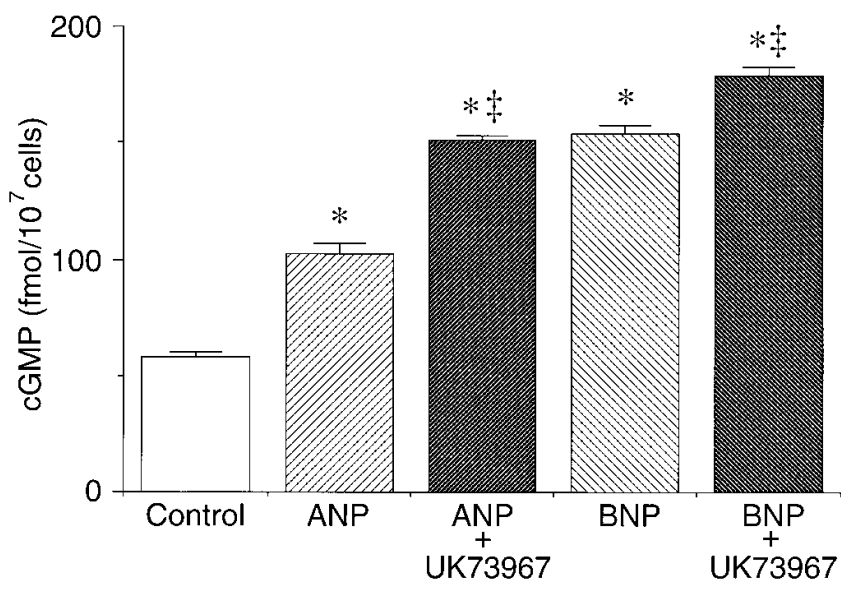

Figure 7. Effects of ANP and BNP in the combination with or without UK73967 on cyclic GMP levels in human neutrophils. Details of the method were described in the text. Concentrations of ANP, BNP, and UK73967 were $1 \mathrm{nmol} /$ liter, $1 \mathrm{nmol} /$ liter, and $50 \mu \mathrm{mol} / \mathrm{liter}$, respectively. Values are shown as mean $\pm \operatorname{SEM}(n=5$ in each experiment). ${ }^{*} P<0.01$ vs. control (nontreated neutrophils); ${ }^{\ddagger} P<0.01$ vs. neutrophils treated with ANP $(1 \mathrm{nmol} / \mathrm{liter})$ alone or BNP $(1 \mathrm{nmol} / \mathrm{li}$ ter) alone, respectively.

phils, three peaks were also observed and co-incubation with UK73967 protected ${ }^{125}$ I-ANP against the degradation by the activated neutrophils as shown in Fig. 9.

The effects of $A N P$ and BNP on $\left[\mathrm{Ca}^{2+}\right]_{i}$ during adhesion and at C5a-stimulation in single neutrophils. It has been reported that neutrophils attach and spread with significant change in $\left[\mathrm{Ca}^{2+}\right]_{\mathrm{i}}$ when suspended neutrophils are placed on the tissue culture dish (41-43). Spontaneous intracellular calcium oscillations were observed during the adhesion to the tissue culture dish in most of neutrophils. And $\left[\mathrm{Ca}^{2+}\right]_{i}$ was transiently increased in response to $\mathrm{C} 5 \mathrm{a}$ in most of neutrophils. However the oscillatory activity during the adhesion and the transients of $\left[\mathrm{Ca}^{2+}\right]_{\mathrm{i}}$ in response to $\mathrm{C} 5 \mathrm{a}$ were not observed in all neutrophils examined. These observations were in agreement with previous reports (41-43). Table $\mathrm{V}$ shows that the percentages of number of the oscillatory neutrophils during adhesion and

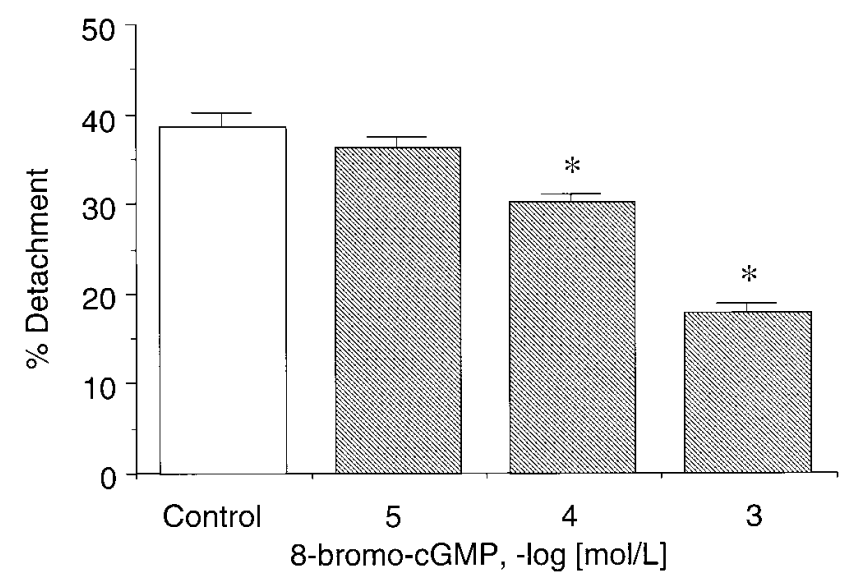

Figure 8. Effect of 8-bromo-cGMP on the endothelial detachment by the activated human neutrophils. Details of the method were described in the text. Values are shown as mean $\pm \operatorname{SEM}(n=6-10)$. $* P<0.01$ vs. control (the activated neutrophils without pretreatment with 8-bromo-cGMP).

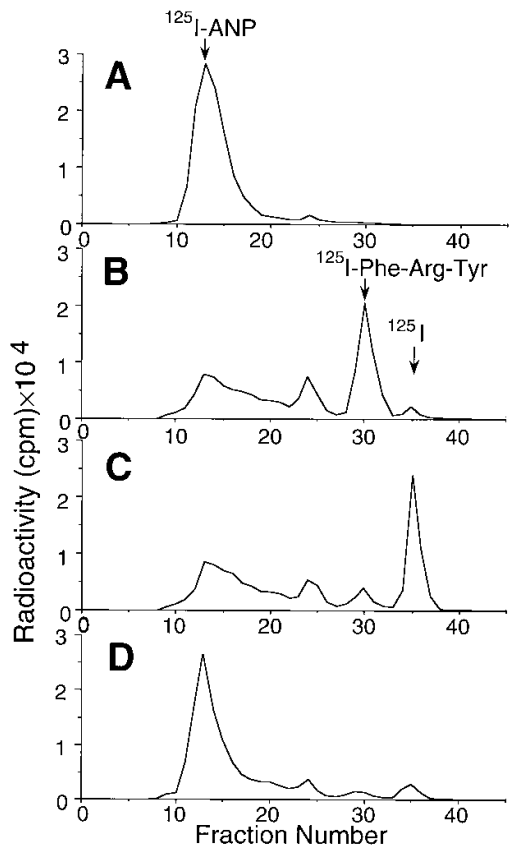

Figure 9. Effect of UK73967 (a specific inhibitor of NEP) on ${ }^{125} \mathrm{I}$ ANP degradation by the activated human neutrophils. (A) Radiochromatograms of ${ }^{125} \mathrm{I}$ ANP after the incubation with the neutrophils-free medium for $15 \mathrm{~min}$ at $37^{\circ} \mathrm{C} .(B)^{125} \mathrm{I}-$ ANP after the incubation with the particulate fraction from the activated neutrophils for $15 \mathrm{~min}$ at $37^{\circ} \mathrm{C}$. (C) ${ }^{125}$ I-ANP after the incubation with the activated neutrophils for $15 \mathrm{~min}$ at $37^{\circ} \mathrm{C}$. (D) $)^{125} \mathrm{I}$ ANP after the incubation with the activated neutrophils for $15 \mathrm{~min}$ at $37^{\circ} \mathrm{C}$ in the presence of UK73967 (a specific

inhibitor of NEP, $50 \mu \mathrm{mol} /$ liter). When ${ }^{125}$ I-ANP was incubated with the particulate fraction of the activated neutrophils or the activated neutrophils, three peaks were observed, and co-incubation with UK73967 protected ${ }^{125}$ I-ANP against the degradation by the activated neutrophils.

the responding neutrophils to the C5a-stimulation were changed by the pretreatments and the changes in response to each of the pretreatments were in parallels with those of the peak $\left[\mathrm{Ca}^{2+}\right]_{\mathrm{i}}$ response to the pretreatments. The pretreatment with ANP or BNP reduced both the oscillatory activity of $\left[\mathrm{Ca}^{2+}\right]_{\mathrm{i}}$ during the adhesion and the transients in $\left[\mathrm{Ca}^{2+}\right]_{\mathrm{i}}$ in response to C5a stimulation with regards to the amplitude of the peaks, as shown in Table V. Co-incubation of the neutrophils with HS-142-1 attenuated the inhibitory effects of ANP or BNP on the peaks in $\left[\mathrm{Ca}^{2+}\right]_{\mathrm{i}}$ (Table $\mathrm{V}$ ). The pretreatment of neutrophils with 8-bromo-cGMP inhibited the oscillatory activity during the adhesion and the transients in $\left[\mathrm{Ca}^{2+}\right]_{i}$ at the C5a-stimulation, mimicking the results obtained from experiments using ANP or BNP (Table V).

In vivo animal experiments. Plasma level of ANP in dogs was increased at $30 \mathrm{~min}$ after the LAD occlusion $(9.3 \pm 2.1 \mathrm{pg} /$ $\mathrm{ml}$ at baseline vs. $147 \pm 35 \mathrm{pg} / \mathrm{ml}$ at $30 \mathrm{~min}$ after the LAD occlusion, $P<0.05$ ). Plasma level of ANP at $30 \mathrm{~min}$ after the first injection of UK73967 or vehicle was significantly higher in dogs with UK73967 treatment than in those without UK73967 treatment $(695 \pm 135 \mathrm{pg} / \mathrm{ml}$ with UK73967 vs. $167 \pm 40 \mathrm{pg} / \mathrm{ml}$ without UK73967, $P<0.05)$. NEP immunoreactivity and enzymatic activity were found to exist in the isolated neutrophils from the dogs by the same methods as used in the human neutrophils, described in the Methods section, and the immunoreactivity and the enzymatic activity in the dog neutrophils were also up-regulated with C5a-stimulation by 2.6- and 2.2-fold of those at baseline, respectively (cell surface immunoreactive NEP/CD10 expression by flow cytometry at baseline, $5.4 \pm 0.3$ mean channel fluorescence intensity. NEP activity at baseline, $0.1 \pm 0.03 \mathrm{nmol} / \mathrm{min} / \mathrm{mg}$ protein). Furthermore, the enzymatic activity in the dog neutrophils from the peripheral circulation was also increased after the myocardial ischemia/reperfusion 


\begin{tabular}{lcc}
\hline \multirow{2}{*}{\multicolumn{1}{c}{ Pretreatments }} & \multicolumn{2}{c}{${\text { Peak }\left[\mathrm{Ca}^{2+}\right]_{\mathrm{i}}(\mathrm{nmol} / \mathrm{L})}^{\text {At C5a-Stimulation }}$} \\
\cline { 2 - 3 } & \multicolumn{1}{c}{ During adhesion } & $\begin{array}{c}\text { No.responding cells/ } \\
\text { No.cells studied, } \%\end{array}$ \\
No pretreatment & $\begin{array}{c}\text { No.oscillatory cells/ } \\
\text { No.cells studied, } \%\end{array}$ & $311 \pm 12(14 / 19,74 \%)$ \\
ANP & $232 \pm 11(15 / 20,75 \%)$ & $176 \pm 10^{*}(9 / 22,41 \%)$ \\
BNP & $157 \pm 10^{*}(10 / 24,42 \%)$ & $170 \pm 12 *(10 / 23,44 \%)$ \\
ANP+HS-142-1 & $152 \pm 15^{*}(10 / 23,43 \%)$ & $288 \pm 15^{\ddagger}(17 / 24,70 \%)$ \\
BNP+HS-142-1 & $207 \pm 12^{\ddagger}(16 / 22,73 \%)$ & $281 \pm 13^{\S}(13 / 21,61 \%)$ \\
8-bromo-cGMP[0.1 mmol/L] & $199 \pm 15^{\S}(15 / 22,68 \%)$ & $232 \pm 10^{*}(11 / 19,58 \%)$ \\
8-bromo-cGMP[1 mmol/L] & $190 \pm 11^{*}(9 / 18,50 \%)$ & $213 \pm 12 *(9 / 19,47 \%)$ \\
\hline
\end{tabular}

Values within parentheses are number of the oscillatory cells during adhesion and the responding cells at C5a-stimulation and all neutrophils studied. Peaks in $\left[\mathrm{Ca}^{2+}\right]_{\mathrm{i}}$ during adhesion and at C5a-stimulation were statistically analyzed and shown in this Table in the cells that showed the oscillatory activity and the transients of $\left[\mathrm{Ca}^{2+}\right]_{\mathrm{i}}$ in the respective conditions. Concentrations of ANP, BNP, and HS-142-1 were $1 \mathrm{nmol} / /$ iter, $1 \mathrm{nmol} / \mathrm{liter}$, and 100 $\mu \mathrm{g} / \mathrm{ml}$, respectively. Values of peak $\left[\mathrm{Ca}^{2+}\right]_{\mathrm{i}}(\mathrm{nmol} / \mathrm{liter})$ were taken from ten different preparations of neutrophils and are shown as mean $\pm \mathrm{SEM}$. $* P<0.01$ vs. no pretreatment; ${ }^{\ddagger} P<0.01$ vs. ANP; ${ }^{\S} P<0.01$ vs. BNP.

by 2.1-fold of that at baseline. MPO activity, an indicator of neutrophils accumulation, in the ischemic/reperfused myocardial region was significantly lower in dogs with UK73967 treatment than in those without UK73967 treatment, as shown in Fig. 10. The study with light microscopy showed that there were numerous neutrophils infiltrates within vascular lumens and in the interstitium from dogs without UK73967 treatment, whereas there were only rare neutrophils present in capillaries and in the interstitium from dogs with UK73967 treatment, as shown in Fig. 11. The study with scanning electron microscopy showed that there were numerous neutrophils adhered to the coronary arterial endothelium from dogs without UK73967 treatment, whereas there were only occasional neutrophils ad-

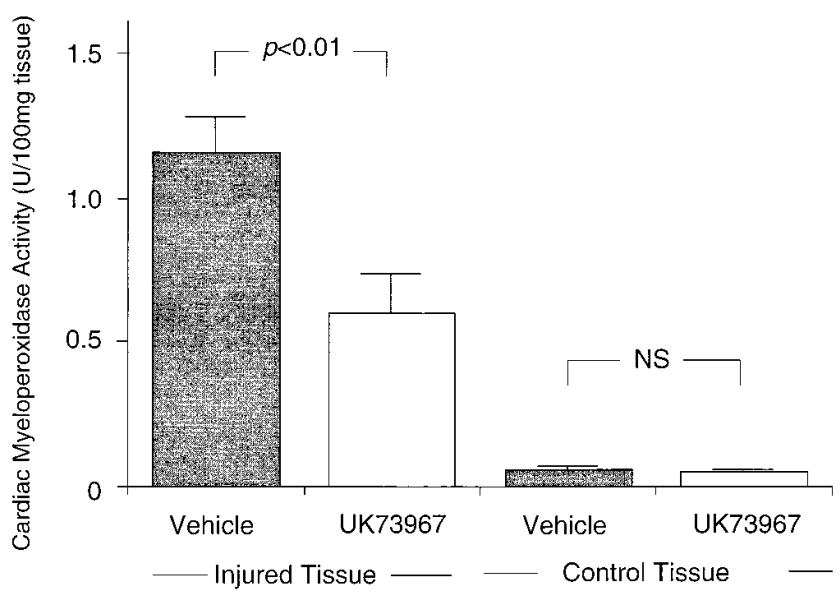

Figure 10. Effect of UK73967 treatment on cardiac MPO activity in an in vivo canine model of myocardial ischemia/reperfusion. Regional myocardial ischemia was produced by occluding LAD for 90 min and was followed by $2 \mathrm{~h}$ of reperfusion. UK73967 $(1 \mathrm{mg} / \mathrm{kg})(n=$ 7 dogs) or its vehicle ( $n=7$ dogs) was intravenously administered as a bolus twice during the myocardial ischemia/reperfusion experiments. The myocardial tissues were taken from the regions injured by the ischemia/reperfusion (Injured Tissue) and the normal perfused region (Control Tissue) and were subjected to the assay of MPO activity. Values are shown as mean \pm SEM. hered to the endothelium from dogs with UK 73967 treatment, as shown in Fig. 12.

\section{Discussion}

The present study showed that ANP and BNP at the concentrations of $0.1-10 \mathrm{nmol} /$ liter inhibited the detachment of the cultured endothelial cells by the neutrophils and the adhesiveness of the neutrophils to the endothelial cells. The present study also showed that the inhibitory effects of ANP and BNP were associated with the suppressions of CD18 expression on the neutrophils and of elastase release from the neutrophils. CD18 expression and elastase release of neutrophils are wellknown to have important roles in the adhesion of neutrophils to the endothelium and subsequent endothelial injury $(27,28$, $48,49)$. Furthermore, we have previously shown that CD18 expression on the neutrophils and elastase release from the neutrophils play an essential role in the adhesion of the neutrophils to the endothelium and neutrophils-induced endothelial cytotoxity (32). Therefore, the suppressions of CD18 expression and of elastase release by ANP and BNP may at least partly contribute to the inhibitory effects of ANP and BNP on neutrophils adhesion and cytotoxity to the endothelial cells. Although the exact mechanisms responsible for the suppression on the neutrophil functions by ANP and BNP still remain to be elucidated, cGMP produced in neutrophils by ANP and BNP via particulate guanylyl cyclase may play a role in the mechanism of the suppressive effects of ANP and BNP. Because the present study also demonstrated that HS-142-1, an antagonist for the particulate guanylyl cyclase receptor (50, 51), attenuated the suppressive effects of ANP and BNP, and the present study showed that 8-bromo-cGMP also inhibited the neutrophils-induced endothelial detachment and elastase release from the neutrophils, mimicking the effects observed with ANP and BNP. Thus, it could be assumed that cGMP elevated by ANP and BNP may affect the intracellular processes for the functional alterations in neutrophils during activation with OZ or C5a. Furthermore, the present study showed that ANP and BNP suppressed both of the oscillatory activity of $\left[\mathrm{Ca}^{2+}\right]_{\mathrm{i}}$ during the adhesion and the transients in $\left[\mathrm{Ca}^{2+}\right]_{\mathrm{i}}$ in re- 

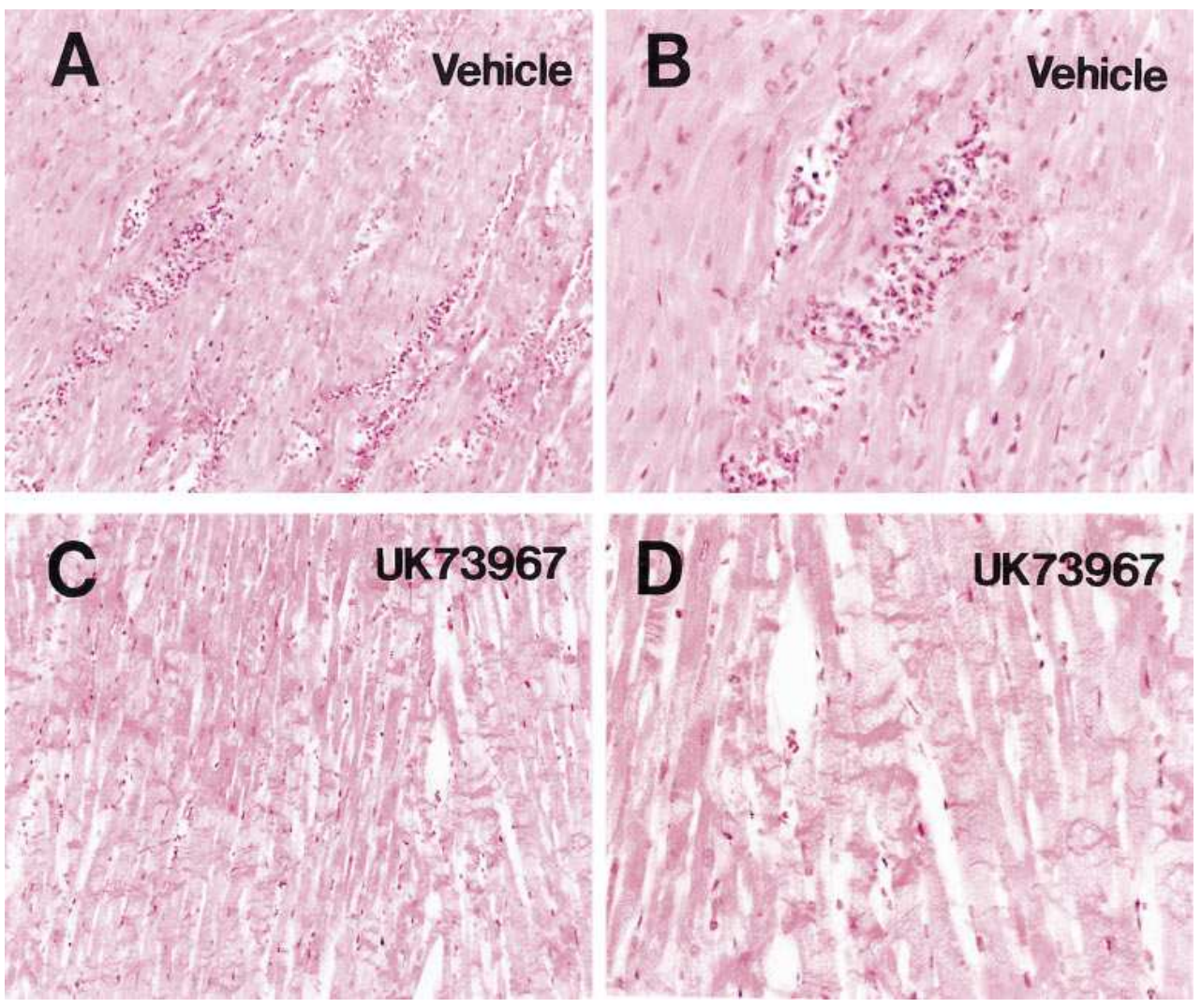

Figure 11. Light micrographs of the ischemic/reperfused myocardial tissues in an in vivo canine model. ( $A$ and $B$ ) Light micrographs of ischemic/reperfused myocardium from the dog without UK73967 treatment. Intense accumulation of neutrophils in the microvessels and the transmigration of neutrophils were apparent in the myocardium injured by ischemia/reperfusion $(A, \times 200, B, \times 400) .(C$ and $D)$ Light micrographs of ischemic/ reperfused myocardium from the dog with UK73967 treatment. Neutrophil accumulation in the microvessels and the extravascular neutrophils were much less as compared with $A$ and $B(C, \times 200 ; D, \times 400)$. Findings showing in $A-D$ are representative of those observed in the ischemic/reperfused myocardium of the dogs treated with or without UK73967. sponse to C5a-stimulation in neutrophils. These suppressions also appear to be mediated by cGMP since HS-142-1 attenuated the suppressive effects of ANP and BNP on $\left[\mathrm{Ca}^{2+}\right]_{i}$, and 8-bromo-cGMP exhibited mimicking effects on $\left[\mathrm{Ca}^{2+}\right]_{\mathrm{i}}$ in neutrophils as observed with ANP and BNP. A rise in $\left[\mathrm{Ca}^{2+}\right]_{\mathrm{i}}$ has been implicated to have a regulatory role in various functions including adherence and elastase release in the neutrophils at rest and at the agonists-stimulation (41-43). Thus, cGMPmediated inhibition of intracellular calcium mobilization may be at least partially involved in the mechanisms by which ANP and BNP suppressed the neutrophil functions. Previous studies showed that cGMP inhibits the receptor-mediated intracellular signaling pathway leading to increase in $\left[\mathrm{Ca}^{2+}\right]_{\mathrm{i}}$ at the levels of protein kinase $\mathrm{C}(\mathrm{PKC})$ or $\mathrm{G}$ protein in various types of

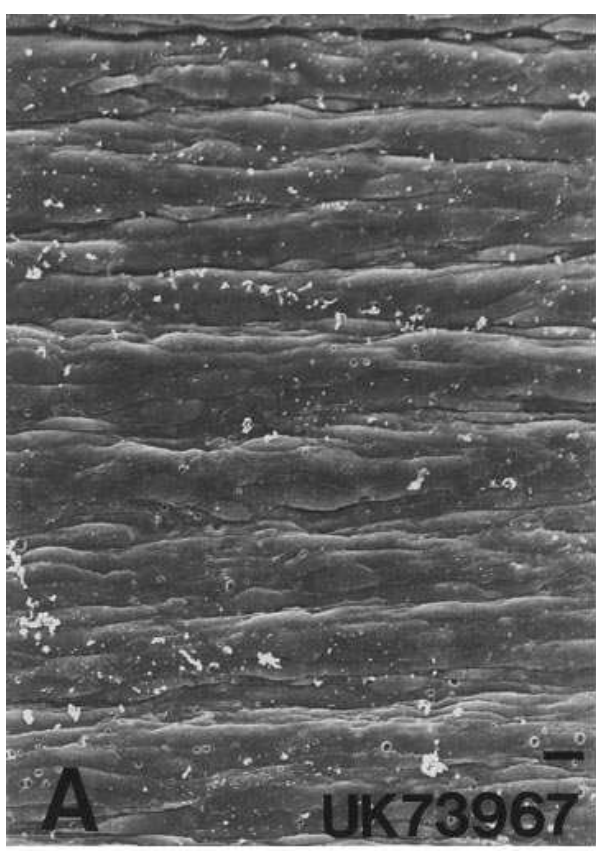

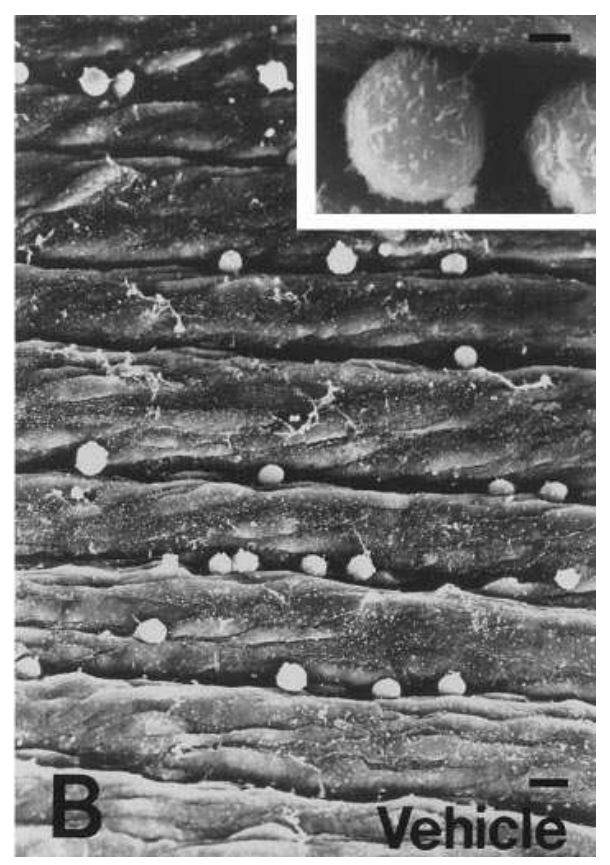

Figure 12. Scanning electron micrographs of the luminal surface of the ischemic/reperfused coronary arteries in an in vivo canine model. (A) Scanning electron micrograph of the ischemic/reperfused coronary arteries from the dog with UK73967 treatment. There were only occasional neutrophils adhered to the endothelium (Bar, 10 $\mu \mathrm{m})$. (B) Scanning electron micrograph of the ischemic/reperfused coronary arteries from the dog without UK73967 treatment (Bar, $10 \mu \mathrm{m})$. There were numerous neutrophils adhered to the coronary arterial endothelium. ( $B$, inset) Higher magnification illustrates neutrophils adhered to the endothelium (Bar, $60 \mu \mathrm{m}$ ). Findings shown in $A$ and $B$ are representative of those observed in the ischemic/reperfused coronary arteries of the dogs treated with or without UK73967. 
cells $(52,53)$, however, the exact role of cGMP in the signaling pathway in neutrophils is controversial (54-56). Thus, it remains undetermined at the present time which levels of the signaling pathways leading to increase in $\left[\mathrm{Ca}^{2+}\right]_{i}$ in neutrophils may be affected by ANP and BNP. The effects of ANP and BNP on the neutrophil functions seems to be selective, because ANP and BNP had no effect on the respiratory burst action. It has been shown that there may be two distinct signal transduction pathways for the activation of the respiratory burst: one is $\mathrm{Ca}^{2+}$-dependent and leads to PKC activation; the other is $\mathrm{Ca}^{2+}$-independent and does not involve phospholipase $\mathrm{C}$ or PKC (57). It is thus possible that the $\mathrm{Ca}^{2+}$-independent pathway may remain functional for the activation of the respiratory burst in the neutrophils treated with ANP and BNP.

We have previously shown that plasma levels of ANP and $\mathrm{BNP}$ increase to the concentrations of $0.01-0.03 \mathrm{nmol} / \mathrm{liter}$ and $0.03-0.1 \mathrm{nmol} / \mathrm{liter}$, respectively, in the peripheral blood and to the concentrations of $0.3-0.6 \mathrm{nmol} /$ liter and $0.8-2.0 \mathrm{nmol} / \mathrm{liter}$, respectively, in the coronary sinus blood in patients with AMI (8). We have also reported that intravenous infusion of ANP or BNP improves left ventricular function in patients with congestive heart failure by the mechanisms of vasodilatation and natriuretic action $(58,59)$. Furthermore, we have previously demonstrated that intracoronary infusion of BNP dilates coronary arteries in vivo humans (60). Thus, ANP and BNP appear to exert the beneficial effects on cardiac hemodynamics. Myocardial ischemia/reperfusion in AMI causes not only myocardial injury but also coronary vascular injury which results in further myocardial damage. It has been shown that neutrophils play a role in those setting, and that the adhesion of neutrophils to coronary endothelium and the subsequent endothelial injury by neutrophils are important steps in the coronary vascular injury occurring in the condition of myocardial ischemia and reperfusion in AMI. Therefore, considering our previous reports and the present results showing that ANP and BNP at the concentrations elevated in the coronary or peripheral circulations in patients with AMI inhibit neutrophils-induced endothelial injury, ANP and BNP elevated in the coronary circulation and in the circulatory peripheral plasma in patients with AMI could exert protective actions on the neutrophils-induced coronary vascular injury and could lead to salvage ischemic myocardium.

NEP has been shown to exist on the surface membrane of neutrophils and hydrolyze ANP and BNP. The present study demonstrated that NEP expression was up-regulated on the surface membrane of neutrophils activated with $\mathrm{OZ}$ or C5a and on that of the circulating neutrophils in the patients with early phase of AMI. Furthermore, the present study also demonstrated that the activated neutrophils induced ANP degradation which was attenuated with UK73967, a specific NEP inhibitor. The present study also showed that the inhibitory effects of ANP and BNP on the functions of the activated neutrophils were potentiated with NEP inhibitors. Therefore, the present results indicate that ANP and BNP exert protective effects against the neutrophils-induced endothelial injury, but the effects are suppressed by neutrophil NEP which also increases after their activation with $\mathrm{OZ}$ or $\mathrm{C} 5 \mathrm{a}$ or in AMI. In this context, NEP inhibitors might have a rationale for therapeutic agent preventing neutrophils-induced endothelial injury in AMI. In fact, the present in vivo dog experiment showed that UK73967 treatment suppressed both the adhesion to endothelium and the accumulation of neutrophils in the ischemic/re- perfused coronary vasculature and myocardial tissue. These inhibitory effects of UK73967 in vivo treatment on neutrophilrelated activities (adherence to coronary vascular endothelium, accumulation in the vasculature and myocardial tissue) were at least partially mediated by the inhibition of neutrophil NEP since the present in vivo dog experiment also showed that NEP was expressed in dog neutrophils and up-regulated in the circulated peripheral dog neutrophils after the myocardial ischemia/reperfusion and in the isolated dog neutrophils after C5a activation. The present and other studies with in vivo human and animals show that levels of ANP in the peripheral circulation were increased after systemic administration of NEP inhibitor $(61,62)$. Thus, NEP inhibitor might inhibit neutrophils-mediated endothelial and myocardial injury and improve cardiac hemodynamics through the effect of ANP and BNP increased locally on the surface of neutrophils and systematically in the peripheral circulation by inhibition of NEP in neutrophils and in other organs.

The present results are in agreement with the previous reports by Shipp et al. and other workers showing that the responses of neutrophils to inflammatory peptides including FMLP and substance $P$ were influenced by NEP in neutrophils themselves (14-16). A report showed that ANP weakly enhanced respiration burst activity and granule release in neutrophil response to FMLP (63). The stimulative effects of ANP on neutrophils, in that report, were independent of cGMP and were not affected by NEP in neutrophils themselves, which are in contrast with the results in the present study and in other papers (14-16). The reason for the discrepancy is unclear, but the difference in the incubating conditions and in the stimulations tested may be one of the possible reasons. They suspended neutrophils in Hanks' balanced salt solution (HBSS) while we and other workers used the culture medium such as RPMI and Medium 199 which are more physiological than HBSS. When they incubated neutrophils in culture medium of RPMI for chemotaxis assay instead of HBSS which was used for the other assays of the respiration burst activity and the granule release in the report, they showed that ANP did inhibit chemotactic activity of neutrophils in response to FMLP.

As suggested in the present study, neutrophils in patients with AMI might reduce the responses to a variety of NEP degradable peptides such as endothelin and bradykinin so on (64, 65). However, the exact mechanisms for the up-regulation of NEP in the surface membrane of neutrophils in patients with AMI remains undetermined in the present study. There are a number of reports showing that neutrophils present in the injured myocardium as well as in the circulation in AMI are on the state of activation (66). In the present in-vitro experiment, we used $\mathrm{OZ}$ for the neutrophils activation since $\mathrm{OZ}$ is a potent activator of the alternative pathway of complements, and the activation of the complement system has been shown to play a role in the neutrophils-induced myocardial injury in AMI (67, 68). In fact, the complement C5a was reported to be produced during myocardial ischemia and reperfusion via activation of neutrophils (67). And further, the present study showed that up-regulation of NEP expression was induced by $\mathrm{OZ}$ in neutrophils in the comparable magnitude observed with that by C5a and in early phase of AMI. Thus, complements-induced up-regulation of NEP may be one of the possible mechanisms for the increase expression of neutrophil NEP in AMI. The present study showed that up-regulation of NEP expression on the surface membrane of neutrophils after activation with $\mathrm{OZ}$ 
seems to be independent on the de-novo protein synthesis and mRNA transcription because cycloheximide and actinomycin $D$ were ineffective on the NEP up-regulation on the activated neutrophils. The increase in particulate NEP activity was associated with the decrease in the cytosol NEP activity without changes of total NEP activity in the neutrophils activated with OZ. The similar response of the intracellular NEP activities was observed with neutrophils from patients with early phase of AMI, comparing with neutrophils from patients with late phase of AMI and from control subjects. These present findings indicate that the up-regulation of NEP expression on the surface membrane of neutrophils after activation with $\mathrm{OZ}$ and of those from patients with AMI may be caused by the translocation of NEP to the plasma membrane from the intracellular compartments, supporting the results reported by Werfel et al. (69) who used C5a for the neutrophils activation.

In conclusion, ANP and BNP, which increase in AMI, modulate the neutrophil functions and exert protective effects against the neutrophils-induced endothelial cytotoxity at the physiological concentrations. But the effects are suppressed due to their degradation by the neutrophil own NEP. Thus, neutrophil NEP, which also increases in AMI, may play a role in the pathophysiology of ischemia/reperfusion myocardial injury.

\section{Acknowledgments}

We thank Dr. Akira Hirata (Div. of Ophthalmology, Kumamoto University), and Dr. Yasuhiro Ogata (Japanese Red Cross Kumamoto Hospital).

This work was supported in part by the Grant-in-aid for Scientific Research on C07670793 from the Ministry of Education, Science and Culture in Japan.

\section{References}

1. de Bold, A.J. 1985. Atrial natriuretic factor: a hormone produced by the heart. Science (Wash. DC). 230:767-770.

2. Laragh, J.H. 1985. Atrial natriuretic hormone: the renin aldosterone axis and blood pressure-electrolyte homeostasis. N. Engl. J. Med. 313:1330-1340.

3. Needleman, P., and J.E. Greenwald. 1986. Atriopeptin: a cardiac hormone intimately involved in fluid, electrolyte, and blood pressure homeostasis. N. Engl. J. Med. 314:828-834.

4. Ballermann, B.J., and B.M. Brenner. 1986. Role of atrial peptides in body fluid homeostasis. Circ. Res. 58:619-630.

5. Genest, J., and M. Cantin. 1987. Atrial natriuretic factor. Circulation. 75(suppl I): I-118-I-124.

6. Floras, J.S. 1990. Sympathoinhibitory effects of atrial natriuretic factor in normal humans. Circulation. 81:1860-1873.

7. Yasue, H., M. Yoshimura, H. Sumida, K. Koichi, K. Kugiyama, M. Jougasaki, H. Ogawa, K. Okumura, M. Mukoyama, and K. Nakao. 1994. Localization and mechanism of secretion of B-type natriuretic peptide in comparison with those of A-type natriuretic peptide in normal subjects and patients with heart failure. Circulation. 90:195-203.

8. Morita, E., H. Yasue, M. Yoshimura, H. Ogawa, M. Jougasaki, T. Matsumura, M. Mukoyama, and K. Nakao. 1993. Increased plasma levels of brain natriuretic peptide in patients with acute myocardial infarction. Circulation. 88: 82-91.

9. Omland, T., T. Aarsland, A. Aakvaag, R. T. Lie, and K. Dickstein. 1993. Prognostic value of plasma atrial natriuretic factor, norepinephrine and epinephrine in acute myocardial infarction. Am. J. Cardiol. 72:255-259.

10. Yasue, H., K. Obata, K. Okumura, M. Kurose, H. Ogawa, K. Matsuyama, M. Jougasaki, Y. Saito, K. Nakao, and H. Imura. 1989. Increased secretion of atrial natriuretic polypeptide from the left ventricle in patients with dilated cardiomyopathy. J. Clin. Invest. 83:46-51.

11. Erdös, E.G., and R.A. Skidgel. 1989. Neutral endopeptidase 24.11 (enkephalinase) and related regulators of peptide hormones. FASEB. J. 3:145-151.

12. Johnson, A.R., J. Ashton, W.W. Schultz, and E.G. Erdös. 1985. Neutral metalloendopeptidase in human lung tissue and cultured cells. Am. Rev. Respir. Dis. 132:564-568.
13. Malfroy, B., J.P. Swerts, A. Guyon, B.P. Roques, and J.C. Schwartz. 1978. High-affinity enkephalin-degrading peptidase in brain is increased after morphine. Nature (Lond.). 276:523-526.

14. Connelly, J.C., R.A. Skidgel, W.W. Schulz, A.R. Johnson, and E.G. Erdös. 1985. Neutral endopeptidase 24.11 in human neutrophils: cleavage of chemotactic peptide. Proc. Natl. Acad. Sci. USA. 82:8737-8741.

15. Shipp, M.A., G. B. Stefano, L. D'Adamio, S.N. Switzer, F.D. Howard, J. Sinisterra, B. Scharrer, and E.L. Reinherz. 1990. Downregulation of enkephalin-mediated inflammatory responses by CD10/neutral endopeptidase 24.11 . Nature (Lond.). 347:394-396.

16. Shipp, M.A., G.B. Stefano, S.N. Switzer, J.D. Griffin, and E.L. Reinherz. 1991. CD10 (CALLA)/Neutral endopeptidase 24.11 modulates inflammatory peptide-induced changes in neutrophil morphology, migration, and adhesion proteins and is itself regulated by neutrophil activation. Blood. 78:18341841.

17. Iwamoto, I., A. Kimura, K. Ochiai, H. Tomioka, and S. Yoshida. 1991. Distribution of neutral endopeptidase activity in human blood leukocytes. $J$. Leukocyte Biol. 49:116-125.

18. Letarte, M., S. Vera, R. Tran, J.B.L. Addis, R.J. Onizuka, E.J. Quackenbush, C.V. Jongeneel, and R.R. McInnes. 1988. Common acute lymphocytic leukemia antigen is identical to neutral endopeptidase. J. Exp. Med. 168:12471253.

19. Shipp, M.A., N.E. Richardson, P.H. Sayre, N.R. Brown, E.L. Masteller, L.K. Clayton, J. Ritz, and E.L. Reinherz. 1988. Molecular cloning of the common acute lymphoblastic leukemia antigen (CALLA) identifies a type II integral membrane protein. Proc. Natl. Acad. Sci. USA. 85:4819-4823.

20. Willerson, J.T., J.T. Watson, I. Hutton, G.H. Templeton, and D.E. Fixler. 1975. Reduced myocardial reflow and increased coronary vascular resistance following prolonged myocardial ischemia in the dog. Circ. Res. 36:771781.

21. Ku, D.D. 1982. Coronary vascular reactivity after acute myocardial ischemia. Science (Wash. DC). 218:576-578.

22. VanBenthuysen, K.M., I.F. McMurtry, and L.D. Horwitz. 1987. Reperfusion after acute coronary occlusion in dogs impairs endothelium-dependent relaxation to acetylcholine and augments contractile reactivity in vitro. J. Clin. Invest. 79:265-274.

23. Tsao, P.S., N. Aoki, D.J. Lefer, G. Johnson, and A.M. Lefer. 1990. Time course of endothelial dysfunction and myocardial ishemia and reperfusion in the cat. Circulation. 82:1402-1412.

24. Lefer, A.M., P.S. Tsao, D.J. Lefer, and X. Ma. 1991. Role of endothelial dysfunction in the pathogenesis of reperfusion injury after myocardial ischemia. FASEB J. 5:2029-2034.

25. Mehta, J., J. Dinerman, P. Mehta, T.G.P. Saldeen, D. Lawson, W.H. Donnelly, and R. Wallin. 1989. Neutrophil function in ischemic heart disease. Circulation. 79:549-556.

26. Servi, S.D., A. Mazzone, G. Ricevuti, A. Fioravanti, E. Bramucci, L. Angoli, G. Stefano, and G. Specchia. 1990. Granulocyte activation after coronary angioplasty in humans. Circulation. 82:140-146.

27. Inauen, W., D.N. Granger, C.J. Meininger, M.E. Schelling, H.J. Granger, and P.R. Kvietys. 1990. Anoxia-reoxygen-induced, neutrophil-mediated endothelial cell injury: role of elastase. Am. J. Physiol. 259:H925-H931.

28. Harlan, J.M., P.D. Killen, L.A. Harker, and G.E. Striker. 1981. Neutrophil-mediated endothelial injury in vitro. Mechanisms of cell detachment. $J$. Clin. Invest. 68:1394-1403.

29. Roques, B.P., F. Noble, V. Dauge, M.C. Fournie-Zalunski, and A. Beaumont. 1993. Neutral endopeptidase 24.11: structure, inhibition, and experimental and clinical pharmacology. Pharmacol. Rev. 45:87-146.

30. Hudgin, R.L., S.E. Charleson, M. Zimmerman, R. Mumford, and P.L. Wood. 1981. Enkephalinase: selective peptide inhibitors. Life Sci. 29:2593-2601.

31. Danilewicz, J.C., P.L. Barclay, I.T. Barnish, D. Brown, S.F. Campbell, K. James, G.M.R. Samuels, N.K. Terrett, and M.J. Wythes. 1989. UK-69,578, a novel inhibitor of EC 3.4.24.11 which increases endogenous ANF levels and is natriuretic and diuretic. Biochem. Biophys. Res. Commun. 164:58-65.

32. Sugiyama, S., K. Kugiyama, M. Ohgushi, K. Fujimoto, and H. Yasue. 1994. Lysophosphatidylcholine in oxidized low-density lipoprotein increases endothelial susceptibility to polymorphonuclear leukocyte-induced endothelial dysfunction in porcine coronary arteries. Role of protein kinase C. Circ. Res. 74:565-575.

33. Kawabata, K., M. Suzuki, M. Sugitani, K. Imaki, M. Toda, and T. Miyamoto. 1991. ONO-5046, a novel inhibitor of human neutrophil elastase. Biochem. Biophys. Res. Commun. 177:814-820.

34. Kugiyama, K., T. Sakamoto, I. Misumi, S. Sugiyama, M. Ohgushi, H. Ogawa, M. Horiguchi, and H. Yasue. 1994. Transferable lipids in oxidized lowdensity lipoprotein stimulate plasminogen activator inhibitor-1 and inhibit tissue-type plasminogen activator release from endothelial cells. Circ. Res. 73: 335-343.

35. Sugama, Y., C. Tiruppathi, K. Janakidevi, T.T. Andersen, J.W. Fenton II, and A.B. Malik. 1992. Thrombin-induced expression of endothelial P-selectin and intercellular adhesion molecule-1: a mechanism for stabilizing neutrophil adhesion. J. Cell Biol. 119:935-944.

36. Zimmerman, B.J., D.C. Anderson, and D.N. Granger. 1992. Neuropeptides promote neutrophil adherence to endothelial cell monolayers. Am. J. 
Physiol. 263:G678-G682.

37. Hughes, H., B. Mathews, M.L. Lenz, and J.R. Guyton. 1994. Cytotoxicity of oxidized LDL to porcine aortic smooth muscle cells is associated with the oxysterols 7-ketocholesterol and 7-hydroxycholesterol. Arterioscler. Thromb. 14:1177-1185.

38. Moldow, C.F., and H.S. Jacob. 1984. Endothelial culture, neutrophil or enzymic generation of free radicals: in vitro methods for the study of endothelial injury. Methods Enzymol. 105:378-385.

39. Vijayaraghavan, J., A.G. Scicli, O.A. Carretero, C. Slaughter, C. Moomaw, and L.B. Hersh. 1990. The hydrolysis of endothelins by neutral endopeptidase 24.11 (enkephalinase). J. Biol. Chem. 265:14150-14155.

40. Gros, C., A. Souque, J.C. Schwartz, J. Duchier, A. Cournot, P. Baumer, and J.M. Lecomte. 1989. Protection of atrial natriuretic factor against degradation: diuretic and natriuretic responses after in vivo inhibition of enkephalinase (EC 3.4.24.11) by acetorphan. Proc. Natl. Acad. Sci. USA. 86:7580-7584.

41. Richter, J., I. Olsson, and T. Andersson. 1990. Correlation between spontaneous oscillations of cytosolic free $\mathrm{Ca}^{2+}$ and tumor necrosis factorinduced degranulation in adherent human neutrophils. J. Biol. Chem. 265: 14358-14363.

42. Laudanna, C., G. Constanitn, P. Baron, E. Scarpini, G. Scarlato, G. Cabrini, C. Dechecchi, F. Rossi, M.A. Cassatella, and G. Berton. 1993. Sulfatides trigger increase of cytosolic free calcium and enhanced expression of tumor necrosis fator- $\alpha$ and interleukin- 8 mRNA in human neutrophils J. Biol. Chem. 269:4021-4026.

43. Jaconi, M.E.E., R.W. Rivest, W. Schlegel, C.B. Wollheim, D. Pittet, and P.D. Lew. 1988. Spontaneous and chemoattractant-induced oscillations of cytoslic free calcium in single adherent human neutrophils. J. Biol. Chem. 263: 10557-10560.

44. Grynkiewicz, G., M. Poenie, and R. Y.Tsien. 1985. A new generation of $\mathrm{Ca}^{2+}$ indicators with greatly improved fluorescence properties. J. Biol. Chem. 260:3440-3450.

45. Buerke, M., A.S. Weyrich, Z. Zheng, F.C.A. Gaeta, M.J. Forrest, and A.M. Lefer. 1994. Sialyl lewis ${ }^{\mathrm{x}}$-containing oligosaccharide attenuates myocardial reperfusion injury in cats. J. Clin. Invest. 93:1140-1148.

46. Ma, X-L., D.J. Lefer, A.M. Lefer. Baron, and R. Rothlein. 1992. Coronary endothelial and cardiac protective effects of a monoclonal antibody to intercellular adhesion molecule-1 in myocardial ischemia and reperfusion. Circulation. 86:937-946.

47. Bradley, P.P., D.A. Priebat, R.D. Christensen, and G. Rothstein. 1982. Measurement of cutaneous inflammation: estimation of neutrophil content with an enzyme marker. J. Invest. Dermatol. 78:206-209.

48. Lum, H., L. Gibbs, L. Lai, and A.B. Malik. 1994. CD18 integrin-dependent endothelial injury: effects of opsonized zymosan and phorbol ester activation. J. Leukocyte Biol. 55:58-63.

49. Woodman, R.C., P.H. Reinhardt, S. Kanwar, F.L. Johnston, and P. Kubes. 1993. Effects of human neutrophil elastase (HNE) on neutrophil function in vitro and in inflamed microvessels. Blood. 82:2188-2195.

50. Morishita, Y., T. Sano, K. Ando, Y. Saitoh, H. Kase, K. Yamada, and Y. Matsuda. 1991. Microbial polysaccharide, HS-142-1, competitively and selectively inhibits and binding to its guanylyl cyclase-containing receptor. Biochem. Biophys. Res. Commun. 176:949-957.

51. Park, K.H., and R. Levi. 1994. Hypoxic coronary vasodilatation and cGMP overproduction and blocked by a nitric oxide synthase inhibitor, but not by a guanylyl cyclase ANF receptor antagonist. Eur. J. Pharmacol. 256:99-102.

52. Appel, R.G., G.R. Dubyak, and M.J. Dunn. 1987. Effect of atrial natriuretic factor on cytosolic free calcium in rat glomerular mesangial cells. FEBS Lett. 224:396-400.

53. Rogers, J., R.G. Hughes, and E.K. Matthews. 1988. Cyclic GMP inhibits protein kinase C-mediated secretion in rat pancreatic acini. J. Biol. Chem. 263:
3713-3719.

54. Schröder, H., P. Ney, I. Woditsch, and K. Schrör. 1990. Cyclic GMP mediates SIN-1-induced inhibition of human polymorphonuclear leukocytes. Eur J. Pharmacol. 182:211-218.

55. Moilanen, E., P. Vuorinen, H. Kankaanranta, T. Metsä-Ketelä, and H. Vapaatalo. 1993. Inhibition by nitric oxide-donors of human polymorphonuclear leukocyte functions. Br. J. Pharmacol. 109:852-858.

56. Niu, X., C.W. Smith, and P. Kubes. 1994. Intracellular oxidative stress induced by nitric oxide synthesis inhibition increases endothelial cell adhesion to neutrophils. Circ. Res. 74:1133-1140.

57. Dewald, B.M., M. Thelen, and M. Baggiolini. 1988. Two transduction sequences are necessary for neutrophil activation by receptor agonist. J. Biol. Chem. 263:16179-16184

58. Saito, Y., K. Nakao, K. Nishimura, A. Sugawara, K. Okumura, K. Obata, R. Sonoda, T. Ban, H. Yasue, and H. Imura. 1987. Clinical application of atrial natriuretic polypeptide in patients with congestive heart failure: beneficial effects on left ventricular function. Circulation. 76:115-124.

59. Yoshimura, M. H. Yasue, E Morita, N Sakaino, M. Jougasaki, M. Kurose, M. Mukoyama, Y. Saito, K. Nakao, and H. Imura. 1991. Hemodynamic, renal, and hormonal responses to brain natriuretic peptide infusion in patients with congestive heart failure. Circulation. 84:1581-1588.

60. Okumura, K., H. Yasue, H. Fujii, K. Kugiyama, K. Matsuyama, M. Yoshimura, M. Jougasaki, K. Kikuta, H. Kato, H. Tanaka, H. Sumida, and K. Nakao. 1995. Effects of brain (B-type) natriuretic peptide on coronary artery diameter and coronary hemodynamic variables in humans: comparison with effects on systemic hemodynamic variables. J. Am. Coll. Cardiol. 25:342-348.

61. Münzel, T., S. Kurz, J. Holtz, R. Busse, H. Steinhauer, J. Hanjörg, and D. Helmut. 1992. Neurohormonal inhibition and hemodynamic unloading during prolonged inhibition of ANF degradation in patients with severe chronic heart failure. Circulation. 86:1089-1098.

62. Seymour, A.A., M.M. Asaad, V.M. Lanoce, S.A. Fennell, H.S. Cheung, and W.L. Rogers. 1993. Inhibition of neutral endopeptidase 3.4.24.11 in conscious dogs with pacing induced heart failure. Cardiovasc. Res. 27:1015-1023.

63. Wiedermann, C.J., M. Niedermühlbichler, and H. Braunsteiner. 1992. Priming of polymorphonuclear neutrophils by atrial natriuretic peptide in vitro. J. Clin. Invest. 89:1580-1586.

64. López Farré, A., A. Riesco, G. Espinosa, E. Digiuni, M.R. Cernadas, V. Alvarez, M. montón, F. Rivas, M.J. Gallego, J. Egido, S. Casado, and C. Caramelo. 1993. Effect of endothelin-1 on neutrophil adhesion to endothelial cells and perfused heart. Circulation. 88:1166-1171.

65. Skidgel, R.A., H.L. Jackman, and E.G. Erdös. 1991. Metabolism of substance P and bradykinin by human neutrophils. Biochem. Pharmacol. 41:1335-1344.

66. Engler, R.L., M.D. Dahlgren, M.A. Peterson, A. Dobbs, and W. Schmid-Schönbein. 1986. Accumulation of polymorphonuclear leukocytes during 3-h experimental myocardial ischemia. Am. J. Physiol. 251:H93-100.

67. Dreyer, W.J., L.H. Michael, T. Nguyen, C.W. Smith, D.C. Anderson, M.L. Entman, and R.D. Rossen. 1992. Kinetics of C5a release in cardiac lymph of dogs experiencing coronary artery ischemia-reperfusion injury. Circ. Res. 71: $1518-1524$.

68. Yasuda, M., K. Takeuchi, M. Hiruma, H. Iida, A. Tahara, H. Itagane, I. Toda, K. Akioka, M. Teragaki, H. Oku, Y. Kanayama, T. Takeda, W.P. Kolb, and J.D. Tamerius. 1990. The complement system in ischemic heart disease. Circulation. 81:156-163.

69. Werfel, T., G. Sonntag, M.H. Weber, and O. Götze. 1991. Rapid increases in the membrane expression of neutral endopeptidase (CD10), aminopeptidase N (CD13), tyrosine phosphatase (CD45), and Fc $\gamma$-RIII (CD16) upon stimulation of human peripheral leukocytes with human C5a. J. Immunol. 147:3909-3914. 